\title{
LA CASACIÓN CIVIL: EL DESAFÍO DE LA CORRECTA RACIONALIZACIÓN Y IURISPRUDENTIA NOVIT CURIA EN UNA FUTURA REFORMA LEGAL*
}

\author{
CIVIL CASSATION: THE CHALLENGE OF A CORRECT \\ RATIONALIZATION AND IURISPRUDENTIA NOVIT CURIA IN A \\ FUTURE LEGAL AMENDMENT
}

\section{Carlos del Río Ferretti ${ }^{* *}$}

RESUMEN: Este estudio trata la cuestión problemática de los diversos medios procesales para la racionalización del acceso a un recurso de naturaleza casacional, centrándose específicamente en el análisis de los medios de selección de recursos más conocidos dentro de la tradición jurídico procesal en que se inserta el ordenamiento chileno, los cuales se evalúan en el marco del sistema casacional vigente y de cara a una futura reforma como la propuesta en el Proyecto de Código Procesal Civil, que actualmente se encuentra en tramitación legislativa. Por otra parte, en relación con lo anterior, se postula que cualquier reforma habrá de tener en cuenta la cuestión central de la unificación de la jurisprudencia y el valor jurídico que a ella se le confiera en el sistema casacional chileno que se proyecta. Estas dos cuestiones comprendidas en el objeto del estudio tienen diversos puntos de conexión, los cuales a lo largo del análisis del presente artículo quedan expuestos en sus alcances.

Palabras clave: Casación, selección de recursos, iurisprudentia novit curia.

ABSTRACT: This study deals with the problem of diverse procedural means for the access rationalization to a cassational recourse. Its core deals specifically with the selection means of the best known recourses among our procedural tradition, which are assessed within the current cassational system framework and a future amendment as the one proposed in the Civil Procedural Code Project, which is currently being discussed in Congress. On the other hand, and dealing with the aforementioned, we state that any amendment must keep in mind the central issue about unification and the legal value to be granted to it in the Chilean cassational system being discussed. These two issues comprehended in the object of study have different points of connection. The scope of the later is exposed throughout the present article.

Key words: Cassation, recourses selection, iurisprudentia novit curia.

\footnotetext{
* Este estudio hace parte del Proyecto Fondecyt Regular $N^{\circ} 1131129$, del cual su autor es el investigador responsable.

** Profesor de Derecho procesal de la Facultad de Derecho de la Universidad Católica del Norte, Doctor en Derecho por la Universidad de Valencia. Dirección postal: Larrondo 1281, Coquimbo, Chile. Dirección electrónica: cdrio@ucn.cl
} 


\section{TÉCNICAS LEGALES PARA LA RACIONALIZACIÓN DE LA CARGA DE TRABAJO Y DEL FUNCIONAMIENTO DE LA CASACIÓN}

Con frecuencia encontramos, en nuestro medio, referencias más o menos precisas a la selección de recursos para ante los tribunales superiores de justicia y especialmente para ante la Corte Suprema ${ }^{1}$, las que suelen venir acompañadas con alguna idea muy aproximativa sobre la introducción del certiorari en alguna futura reforma al proceso civil, sugiriéndolo como un avance de cómo se concibe la Corte Suprema y sus funciones y fines institucionales. Creemos que resulta imperioso huir de estos argumentos reduccionistas o simplificados en el análisis procesal. El problema no se ciñe a lo anterior y requiere de la observación más amplia y matizada, al mismo tiempo. El objeto de análisis ha de ser la racionalización de la carga de trabajo y del funcionamiento de la casación. Dentro de este debe indagarse acerca de las técnicas legales (procesales) que se puedan considerar como adecuadas para el propósito referido, las que obviamente no se reducen a la cuestión de la selección discrecional de acceso a la casación, como un dilema del todo o nada. Hay otras técnicas legales orientadas a la racionalización y que deben estar contempladas en un escrutinio científico ecuánime².

Cuánta intervención, cuáles técnicas y con qué intensidad aplicarlas dentro de un ordenamiento procesal específico como el chileno (con características y problemas distintos, desde luego, a los que pueden presentarse en los ordenamientos italiano, francés, español, alemán o estadounidense $)^{3}$ nos obliga a plantearnos cuánta y qué racionalización se demanda por nuestra casación (Corte Suprema). Tenemos la impresión que al seguir las corrientes de pensamiento extranjeras sobre el particular no se hace la reflexión previa indicada, y solemos alinearnos con ideas que responden a unas realidades jurídicas pertenecientes a otras tradiciones jurídicas o con unos niveles de desarrollo muy diversos del que exhibe el Derecho chileno. Dudamos que en el sistema chileno el principal problema de la Corte Suprema, ocasionado por la casación, sea el de la cantidad de asuntos en casación: vale decir, ponemos $^{4}$ en duda una pretendida masividad de la casación, como una realidad desborda$\mathrm{da}^{5}$. El principal problema puede ser de trabajo racional y de calidad del mismo, pero no de exceso de carga. Esta es una cuestión que ha de servir de marco a cualquiera reflexión de

\footnotetext{
1 Abreviada también como CS.

2 Chiarloni (1992) p. 25; Ortells (2010) pp. 36-40.

3 Un razonamiento parecido en Rojas (2010) pp. 334-336.

4 Israel (2006) pp. 191-203; Rojas (2010) pp. 330-360. También Del Río (2013) p. 273, y Tavolari (2013) p. 9.

5 Repárese que los datos dados por la misma Corte Suprema parecen apuntar en el sentido indicado. El ministro señor Juan Araya, en su comparecencia el miércoles 17 de julio de 2013, como invitado en la Comisión de Constitución, Legislación y Justicia de la Cámara de Diputados, para exponer sobre el Proyecto de Ley que establece un Nuevo Código Procesal Civil, refiere unos datos muy significativos contenidos en los siguientes términos en el Acta $\mathrm{N}^{\circ}$ 30, Boletín $\mathrm{N}^{\circ}$ 8197-07: «El ministro Araya interviene para referirse a la forma en que ha estado funcionando el recurso de casación en el fondo hoy en la CS. [Se apuntan] Ciertas cifras [que] pueden ser clarificadoras: de 830 recursos de casación ingresados el año 2012, 496 son casación en el fondo, 41 de casación en la forma, y 174 corresponden a recursos en la forma y en el fondo interpuestos conjuntamente. De todos los recursos de casación en el fondo presentados, se han acogido 111 en total; en 21 casos se ha casado de oficio, 215 se han declarado inadmisibles en cuenta y 243 han sido rechazados por manifiesta falta de fundamento».

«Los filtros del sistema, en este sentido, a la luz de las cifras, están operando bien, y solo pasan la admisibilidad los recursos que cumplen los estándares del CPC».
} 
lege ferenda: cuando se piensa en los remedios para la casación, primero hay tener claro cuál es la patología que esta padece y que ha de combatirse.

En este tema, traer este asunto de la selección discrecional como la solución ineludible sobre la casación, solo puede explicarse por el equívoco legislativo y doctrinal de presuponer que la casación en Chile en realidad padece del problema de una saturación de asuntos y un desbordamiento de recursos planteados, completamente incontenible, y como si ni siquiera pudiese ser superado con «los permanentes y cuantiosos medios económicos y de dotación de personal que se destinan a atender ese requerimiento en una sociedad superjudicializada e hiperdemandante de tutela jurisdiccional $»^{6}$. Sin embargo, las realidades jurídica y judicial chilenas están lejos de un paradigma con problemas de esta especie, propios de países con un alto grado de desarrollo jurídico-institucional. Los datos estudiados en frío demuestran que poseemos un exiguo entramado recursivo, con procedimientos simplificadísimos y sumamente abreviados, y además de aquello con una cobertura recursiva incompleta, en donde parcelas relevantes del ordenamiento jurídico nacional y, entonces, de la actividad judicial de mérito, no quedan cubiertos o sometidos a control casacional. Por lo dicho el planteamiento de una cuestión como esta en Chile sin el marco de las realidades jurídica y judicial es en sí mismo un grave error, el cual parece todavía más grave cuando, además, la cuestión de la selección se ha presentado -en la todavía escasa discusión técnicaen términos muy parciales, introduciendo en el debate incluso más confusión sobre lo que se necesita y sobre lo que se quiere hacer.

Dicho lo anterior, el asunto debe ser estudiado en el marco del conjunto de medios jurídico-procesales que buscan o inciden en la racionalización de la carga de trabajo y del funcionamiento de la casación, cuestión que intentaremos analizar desde esta perspectiva seguidamente ${ }^{7}$.

Tocante a los medios de selección o filtros casacionales -según se ha adelantado- estos no tienen siempre los mismos propósito y efecto, y que invariablemente se traduzcan en el impedimento de acceso a la casación, tal como se tiende a presentar el asunto en nuestro medio. Hay también formas de selección que tienen por propósito la diversificación de las formas procesales de intervención casacional, y que incluso pueden suponer en ciertos casos la diversificación organizacional de la casación, pero que no impiden el acceso a ella. Por eso desde el punto de vista anotado se pueden distinguir dos tipos de medios diversos de selección:

a) Medios de selección internos. Son aquellos que no privan de acceso a la casación, sino más bien lo suponen. Actúan mediante el establecimiento de procedimientos o cursos procedimentales preferenciales para los asuntos que no requieren de un estu-

\footnotetext{
${ }^{6}$ Las comillas son casi innecesarias, ya que a nadie se le debería escapar que no se trata en realidad de una descripción real del estado de la cuestión en Chile, en donde los hechos muestran unas situaciones material y jurídica bien diversas.

7 Prescindiremos del análisis en este estudio de las técnicas normativas que no están referidas directamente a la regulación procesal u orgánica de la casación, como puede ser por ejemplo la potenciación de la ejecución provisional de la sentencia definitiva de instancia, técnica legal que ciertamente desincentiva la interposición de recursos de casación con fines puramente dilatorios, pero que no es una intervención directa en el régimen de la casación.
} 
dio o revisión profundos de interpretaciones de la norma o de la generación ex novo de estas. También esos cursos procedimentales pueden suponer al tiempo la previsión de modificaciones orgánicas o de organización interna del tribunal de casación, o la previsión de reglas de reparto de competencia funcional.

b) Medios de selección externo. Son aquellos que buscan la racionalización de la carga de trabajo de la casación y la optimización del funcionamiento de esta, mediante el establecimiento de filtros normativos o judiciales que permitan privar de acceso a este medio de impugnación a un conjunto más o menos amplio de asuntos, con lo cual únicamente consienten la entrada a jurisdicción casacional a un grupo determinado de casos respecto de los cuales se justificaría la intervención casacional.

\section{TÉCNICAS DE SELECCIÓN INTERNA EN LA CASACIÓN}

Como hemos señalado, los medios de selección internos operan directamente dentro de la casación, mediante la introducción de procedimientos o cursos preferenciales para el conocimiento y decisión de los asuntos en sede casacional y, en algunos casos, a través de la introducción además de formas de organización interna de la misma sede, diversificada en función del tipo de asunto casacional. Asimismo, podría considerarse una técnica de selección interna la posibilidad de introducir modificaciones que hagan un reparto de competencia funcional diverso en función del tipo o tipos de asuntos planteados ${ }^{8}$.

El fundamento de los filtros de selección internos y de su utilización estriba en que se presentan como un medio adecuado para la armonización de los valores en tensión en la casación. De una parte, la defensa del Derecho objetivo y el ius litigatoris y de otra la unificación de jurisprudencia y la necesidad de trabajo racionalizado, evitando -digamos así- optar por estos últimos en forma excluyente de los primeros por la vía de quitar un conjunto significativo de asuntos del control casacional. Estos medios o filtros como formas de armonización entre esos valores en tensión suelen ser las vías preferentes para conseguir cierta racionalización en los sistemas jurídicos en donde existan condicionamientos constitucionales que puedan imponer márgenes de selección acotados y que impidan la eliminación del acceso a la jurisdicción casacional, como en el caso italiano con su art. 111 de la Constitución italiana.

Sin embargo, con independencia de lo dicho, en general existe un conjunto de propuestas destinadas a introducir mecanismos de esta especie en las diversas regulaciones de la casación y que tienen unos grados de concreción importantes en distintos ordenamientos jurídicos. Veamos cuáles son las principales.

\footnotetext{
8 Silvestri (1992) pp. 211-216; Pivetti (1992) pp. 274-276; Pizzorusso (1992) pp. 181-197; Nieva (2010) pp. 1-39; López (2010) pp. 87-126; OrTells (2010) pp. 36-37. Nótese que estas denominadas técnicas de selección interna no son desconocidas en USA: algunas de ellas se han discutido como propuestas para reformar a las Cortes de Apelaciones intermedias o bien a la propia Corte Suprema Federal, Vid. Wheeler (2004) pp. 254-255 y pp. 262-266. En algunos casos estas medidas de racionalización han sido aplicadas a las Cortes intermedias que pueden seleccionar asuntos para la aplicación de procedimientos recursivos diferenciados.

En una línea semejante y como propuesta de mejora en el sistema de Reino Unido, Le SuEUR (2004) pp. 290291, refería la necesidad de que la Corte (House of Lord) contar con equipos de abogados (gabinetes de letrados podríamos decir) que intervengan en el mismo procedimiento, todo con el fin de optimizar la capacidad de trabajo que aquella podía absorber.
} 


\subsection{Procedimientos alternativos como cauces procesales preferenciales y simplificados}

Se propone con frecuencia la introducción de cauces procesales preferenciales y simplificados para el conocimiento y decisión de una cierta clase de recursos, que en determinados supuestos pueden ser resueltos por la vía de un procedimiento simplificado y breve, distinto del ordinario más complejo y dilatado, y que demanda entonces más medios y una atención detenida de la Corte. La simplificación supone frecuentemente la utilización de un procedimiento que prescinda de la fase de audiencia pública ante la Corte, con comparecencia de las partes y debate oral.

Ciertamente en Derecho chileno existe un ejemplo claro de este tipo de selección interna, como es el contemplado en el precepto del artículo 782 Código Procesal Civil ${ }^{9}$, que al respecto establece la posibilidad de rechazar por manifiesta falta de fundamento un recurso en fase liminar de control de admisibilidad, con lo cual la ley consiente que aquella fase de admisibilidad mude en la oportunidad para pronunciarse sobre el mérito del asunto planteado, produciéndose la supresión de la fase procedimental ordinaria de conocimiento del asunto en audiencia pública (con comparecencia de las partes a ella y debate oral). La norma en nuestra opinión no es satisfactoria fundamentalmente porque no regula con suficiente detalle una facultad de esta especie. Una reglamentación más cuidadosa podría permitir un uso racional y recto de la misma. Primero, consideramos que convendría regular un específico conocimiento en cuenta que asegurara en forma debida el principio de contradicción. Segundo, sería conveniente ligar la manifiesta falta de fundamento a la existencia de una jurisprudencia asentada de la Corte Suprema, consignando si ello ha de suponer la pluralidad de pronunciamientos (dos o más) y la ausencia de sentencias en oposición dictadas por la misma Corte $^{10}$.

En fin, dadas estas reglas y asegurada la recta aplicación de un medio para conocer y resolver en un curso procedimental abreviado, podría estudiarse seriamente la posibilidad de extender este rito simplificado incluso para la hipótesis positiva, como una vía para acoger recursos cuando exista dicha jurisprudencia asentada a favor del recurrente, previendo únicamente en este supuesto alguna posibilidad -en breve plazo- de discutir por escrito sobre aquella doctrina jurisprudencial. Esta posibilidad potenciaría el uso adecuado de la jurisprudencia consistente y uniforme de la Corte, sin caer desde luego en el argumento incorrecto del efecto vinculante, pues aquel no existe ni para la Corte, que puede abandonar razonadamente su interpretación por otra que la supere, ni para los demás tribunales, que ciertamente pueden discrepar razonadamente de aquella. En último término, de esta manera la regulación permitiría la utilización de la jurisprudencia uniforme en el nivel motivacional o de fundamentación en orden a la correcta determinación, interpretación o aplicación de una norma jurídica, y no como una fuente formal en sí misma. Cuando se acoge o se rechaza un recurso en función de la existencia de la jurisprudencia uniforme lo que hace la Corte es ratificar la interpretación y/o aplicación jurídica que de la ley se haga ${ }^{11}$, ya que

\footnotetext{
9 En adelante CPC.

10 Romero (2004) pp. 63-116; y de él mismo (2013) pp. 195-206.

11 Vid. Silvestri (1992) pp. 212, con referencia a una propuesta legislativa italiana. También NieVA (2010) cit., pp. 31-32. Actualmente Italia aplica el procedimiento cameral (cámara de consejo) más simple que el ordinario en
} 
es esta la fuente formal en sentido propio. Lo atractivo de una medida como esta es que -con las debidas garantías para el principio de contradicción- la Corte podría seleccionar casos para la aplicación de este tipo de procedimiento simplificado, y potenciarlo con otras medidas como puede ser la instalación de gabinetes de letrados que asuman reguladamente una intensa función de auxilio en el conocimiento y decisión de estos asuntos.

\subsection{Tipo y forma de resolución con la que se decide en casación}

En segundo término, en los ordenamientos jurídicos donde la redacción de la sentencia resulta un trabajo normalmente muy demandante, atendidos los elevados niveles de exigencia de fundamentación de las sentencias de casación, aquello resulta una cuestión que en sí mismo se presenta como una causa de atraso y sobrecarga de la casación. De allí que frecuentemente se plantea la necesidad de incidir sobre este extremo, ya introduciendo preceptos que permitan decidir los recursos por resoluciones distintas de las sentencias y menos exhaustivas, ya introduciendo modificaciones a la praxis de redacción de aquellas, por medio de la promoción de determinadas resoluciones más esquemáticas y que demande menos trabajo preparar ${ }^{12}$.

Nótese cómo esta segunda medida de selección interna consistente en una forma de resolución distinta de la sentencia exhaustiva, que consienta la utilización de motivación esquemática - para determinados asuntos en casación-, de algún modo aparece esbozada en la misma norma del art. 782 del CPC, que justamente prevé la posibilidad de utilizar una resolución someramente fundada para la hipótesis de los recursos manifiestamente infundados. Sin embargo, el problema en el modelo chileno es exactamente el inverso al que se pueda encontrar en determinados países europeos (Italia es el ejemplo más claro), en donde la judicatura suele incurrir en el vicio por exceso $-\mathrm{y}$ no por defecto- al insistir en formas de redacción demorosas o lentas, que a menudo se quieren respaldar en el deber de motivación parejo de todos los asuntos en sede casacional, aun cuando aquel deber de motivación no siempre sea necesariamente de la misma intensidad. Por el contrario, las culturas jurídica y judicial chilenas históricamente han sido muy refractarias al deber de conveniente justificación de las decisiones jurisdiccionales, lo cual resulta todavía comprobable en la labor judicial de los tribunales superiores de justicia ${ }^{13}$, de modo que hay que cuidarse del riesgo de que una norma así -en el contexto cultural chileno- no se interprete como una suerte de autorización a la todavía frecuente «motivación apodíctica». Tal cosa efectivamente es un

audiencia pública, para diversos asuntos y en distintas hipótesis. Así, la denominada «apposita sezione» o «sezione filtro" tiene por función el examen preliminar de todos los recursos para determinar si cabe aplicar el rito cameral o el rito ordinario con audiencia pública ante una sección simple o bien ante las secciones unidas. Esta función está íntimamente vinculada a la valoración preliminar de inadmisibilidad, rechazo o estimación que debe hacer un magistrado relator (nombrado al efecto) en función de las hipótesis previstas en el artículo $375 \mathrm{~N}^{\circ}$ s 1 y 5 y art. 360 bis CPCi, y que darán lugar -entre otras- a la aplicación del rito cameral. La inadmisibilidad puede basarse en la existencia de jurisprudencia conforme de la Corte con ausencia de motivos que ofrezcan elementos que requieran la confirmación o modificación de la orientación de la jurisprudencial (arts. 375 párrafo $1^{\circ} \mathrm{N}^{\circ} 5$ y 360.1 del CPCi). Resultan a su turno hipótesis de rechazo o estimación en cámara de consejo los casos en que el recurso sea manifiestamente infundado o -al revés- manifiestamente fundado. Vid. Amoroso (2012) pp. 530-531.

12 Vid. Pivetti (1992) pp. 275-276; Brancaccio (1992) pp. 282 y ss.

13 Denuncia este problema Romero (2004) pp. 100-107. 
riesgo si se considera que la jurisprudencia producida por esta vía contribuye -al ser decisión de fondo- a la generación de doctrina jurisprudencial de la CS, la que incluso puede ser invocada para el conocimiento en pleno, en caso de dispersión jurisprudencial ${ }^{14}$.

Por otra parte, con relación a lo anterior, habría que tener en cuenta que de facto en el funcionamiento actual de la Corte Suprema existiría una medida interna de funcionamiento consistente en entregarle la redacción de las resoluciones que tienen los ministros «en acuerdo» a los relatores que se desempeñan en las salas, quienes asumirían el trabajo de preparación del proyecto de decisión, desde luego bajo la dirección u orientación del ministro redactor, con lo cual en estas hipótesis el relator realizaría en los hechos una función de apoyo relevante, que en otros modelos es asumida por los denominados gabinetes técnicos que auxilian fuertemente la función de decisión de las Cortes ${ }^{15}$. Medidas como estas pueden parecer muy oportunas y justificadas, pero, como se ha sugerido ${ }^{16}$, tales prácticas de gestión interna tienen que estar reconocidas y reguladas, y al mismo tiempo respaldadas por la dotación de personal adecuado, de modo que convendría al efecto establecer entonces un auténtico gabinete de letrados que auxilie a la Corte Suprema e incremente su capacidad de absorber una cantidad importante de asuntos, sin sacrificio de la calidad de las decisiones. De momento sin embargo el Código Orgánico de Tribunales no regula en absoluta una cuestión como esta, y más aún el art. 85 de ese cuerpo legal dispone una cosa distinta de lo que en la práctica estaría ocurriendo.

\subsection{El conocimiento del recurso por colegio restringido como medida de organiza-} ción interna de la Corte de casación, y que además suponga un procedimiento alternativo preferencial

También se suele contemplar como mecanismo de selección interna el conocimiento de recursos por un colegio restringido, lo que permitiría asignar una gama de asuntos a una sala o sección (o como se le llame) integrada con menos jueces que el ordinario, la cual -en un procedimiento simplificado respecto del ordinario- pueda conocer y resolver el recurso de forma más expedita. En este caso, como ya se ha indicado, la selección interna incide además en la organización de la Corte, la que viene adaptada a las necesidades de mayor celeridad para resolver aquellos asuntos que no plantean requerimientos de examen detenido. Mecanismo de esta especie es el que se conoce en el Derecho francés con la denominada formations restreintes (COJ art. L 431-1, al 1) de la Cámara a que se distribuye el asunto y que puede en fase de admisión declararlo inadmisible en tanto el recurso no se funde en un motivo serio de casación, aun cuando aquello en la práctica cubra hipótesis de rechazo del motivo in limine $e^{17-18}$.

\footnotetext{
14 Vid. en este sentido, por ejemplo, Mosquera y Maturana (2010) pp. 316-317.

15 Rojas (2010) pp. 337-338.

16 Rojas (2010) pp. 337-338.

17 Jobard-Bachellier y Bachellier (2006) pp. 13 y ss.; Amrani Mekki (2010) pp. 633-639; Ferrand (2010) p. 590; Couchez y Lagarde (2014) pp. 488-489.

18 Lo que sin embargo no resulta fácilmente contrastable atendida la falta de motivación de la resolución que declara la inadmisibilidad: Jobard-BACHellier y BaCHellier (2006) pp. 13 y ss.; Amrani MeKKi (2010) pp. 633-639.
} 
Silvestri ${ }^{19}$ proponía en Italia algo semejante cuando apuntaba: «El colegio restringido, examinado el recurso, tendría dos posibilidades: o pronunciar el rechazo inmediato del recurso por manifiesta falta de fundamento o por inadmisibilidad de los motivos, o bien, cuando en el recurso se proponga una cuestión sobre la cual exista ya una jurisprudencia consolidada, decidirlo en el mérito acogiéndolo o rechazándolo con un procedimiento, que podría ser (también si no necesariamente) aquel cameral. El tratamiento del recurso ante la sección en su composición ordinaria y pública vendría a ser reservada a los recursos que propongan cuestiones nuevas o de interés general, o bien cuestiones en las que se considere oportuno cambiar la orientación seguida con anterioridad».

Se ha criticado una propuesta de esta especie, porque ella supondría que la selección interna de todos los asuntos que ingresan en casación por parte del colegio restringido podría implicar un esfuerzo de análisis selectivo importante, con lo cual el ahorro de medios y tiempo no se verificaría en realidad. También se ha dicho que esta forma de selección interna tiene el inconveniente que tiende a sofocar la dialéctica necesaria al interior de la Corte, puesto que desincentiva la permanente revisión de los problemas de interpretación y aplicación y elude la profundización, corrección y modificación de las posturas de la misma Corte, lo cual podría llevar a una previsible tendencia a la no meditada ratificación de los criterios precedentes con independencia del acierto de estos ${ }^{20}$.

Creemos que estas objeciones pueden superarse en parte. En cuanto a la duplicación de tiempos y de uso de medios, aquello puede eliminarse previendo la supresión de la selección en sentido estricto por el "colegio restringido» y estableciendo en su lugar más bien un control de verificación sobre los asuntos en orden a constatar si concurren los supuestos específicos previstos en la ley, consintiendo que este pueda conocer sin más -en su procedimiento preferencial- aquellos asuntos que la ley predetermina (preselecciona) objetivamente, dejándole obviamente un poder para derivar el asunto cuando el «colegio restringido" -en contra de lo inicialmente previsto en la ley- estima menester aplicar el procedimiento ordinario, necesario para proceder a un conocimiento detenido del asunto. Este disminuiría al máximo la duplicación de esfuerzo de estudio para la selección, ya que aquello vendría muy precisamente orientado por el legislador. Tal vez el principal riesgo de un mecanismo de esta especie es que podría hacer más plausible la crítica que apunta sobre un pernicioso estímulo de la tendencia a la ratificación poco razonada de los criterios interpretativos preexistentes, desincentivándose de esta manera la permanente revisión o reexamen de los planteamientos jurídicos, y la profundización que da el estudio de las mismas cuestiones en reiteradas ocasiones y que permite ir perfeccionando las interpretaciones y matizarlas o corregirlas en sus extremos discutibles o equívocos. Este riesgo innegable podría ser mitigado con un grado de afinamiento elevado de aquellos criterios de selección establecidos por el legislador, tanto como por criterios claros en virtud de los cuales pueda remitirse el asunto al procedimiento ordinario, ante la sección o sala con composición completa. Con todo, debe reconocerse el riesgo que implica esta propuesta en el contexto judicial chileno tan fuertemente condicionado por los requerimientos prácticos, los que en

19 Vid. Silvestri (1992) pp. 214-215.

20 Vid. Brancaccio (1992) pp. 285-286. 
su conjunto generan - sin duda- un contexto poco propicio para las soluciones jurisprudenciales bien estudiadas desde el punto de vista jurídico.

\subsection{La técnica del reparto de competencia funcional con otros tribunales superiores}

En fin, podemos considerar como un método de selección interno -que no supone entonces la negación de control casacional- el consistente en el reparto de competencia funcional de la Corte con otros tribunales superiores de justicia. Esta medida tiene, sin embargo, un inconveniente evidente como es que la misma rompe con un presupuesto básico de la casación, como es su unidad orgánica, cuestión que se presenta cual condición sine qua non de la nomofilaquia y la unificación jurisprudencial. Esta es una cuestión elemental para el sano funcionamiento casacional, lo cual ya el mismo Calamandrei ${ }^{21}$ apuntaba con particular fuerza respecto de la realidad italiana de su época, en donde todavía se conocían las denominadas «casaciones regionales».

Lo dicho no obstante no significa que no exista forma de conciliar lo más posible la existencia de una casación ante un Tribunal Supremo y de otros órganos que colaboren en la función casacional. Pero aquello requiere de ciertas previsiones normativas. En todo caso, respecto del Derecho chileno se presenta un inconveniente orgánico-estructural bastante evidente como es que las "casaciones regionales» (o sus equivalentes) no podrían estar constituidas por las CCAA si se entiende que el recurso de casación (en el fondo) está previsto para sentencias de segunda instancia y no respecto de las de primera instancia, las que son apelables justamente ante esas mismas CCAA. Este inconveniente -nótese- actualmente no existe en el proceso penal o laboral, al no existir en ellos segunda instancia, lo cual en ningún caso es una apreciación favorable respecto de estas regulaciones que contemplan juicios con instancia única y recursos de naturaleza casacional ante las CCAA, los que en ambos procesos mencionados son deficitarias.

Por lo anterior, una medida como la que comentamos para el proceso civil con un régimen de apelación -en vigor- obligaría a pensar en la introducción de un nivel judicial nuevo en nuestro entramado orgánico judicial, como sería justamente -por ejemplo- una suerte de tribunal superior de justicia con jurisdicción suprarregional. De esta manera sería imaginable el establecimiento de estos tribunales en 3 o 4 territorios a lo largo del país, ubicándose por encima de las CCAA y un peldaño por debajo de la CS. Estos tribunales superiores tendrían que conocer de los recursos de casación con un poder decisorio limitado, consistente en declarar primero la existencia de la jurisprudencia interpretativa de la Corte Suprema sobre la norma presuntamente infringida y la aplicabilidad de ella al caso.

Con esos dos supuestos debería proceder a acoger o rechazar el recurso, o, en caso de no compartir la jurisprudencia o de entender que alguna de las partes ofrece argumentos o antecedentes que hacen discutible la jurisprudencia de la CS, habría de declararlo de este modo y remitir el recurso ante la CS. Lo mismo debe proceder a hacer si entiende que sobre un caso -en contra de lo que sostenga el recurrente- no existe jurisprudencia sentada por la CS. Con un sistema como este se puede conseguir una defensa del Derecho objetivo y la potenciación de la unificación de jurisprudencia. Por lo demás, en un diseño semejante

21 Calamandrei (1945) t. I, pp. 341 y ss, y t. II, pp. 355 y ss. 
la jurisprudencia no es vinculante y puede ser cuestionada por los justiciables y discutida por cualquier tribunal, pero, al mismo tiempo, se evita la dispersión irracional de disímiles criterios jurisprudenciales y se asegura la racionalidad de la evolución jurisprudencial propiciada por y desde la cúspide, lo que garantiza además que esa evolución sea ordenada y coordinada con los niveles inferiores de la judicatura.

Propuestas de esta especie se han realizado permanentemente para distintas realidades jurídicas: así Cappelletti ${ }^{22}$ o Pizzorusso ${ }^{23}$, en Italia, Nieva ${ }^{24}$ o López $^{25}$, para España. Incluso algunas iniciativas semejantes se han planteado en USA ${ }^{26}$.

En lo sustancial la propuesta de Pizzorusso -con algunas modificaciones terminológicas también $\mathrm{Nieva}^{27}$ - imagina secciones o salas que asumirán bajo premisas muy parecidas la función de admisión o decisión que sean de rutina o de fácil resolución, dejando únicamente para la cúspide del entramado judicial aquellos asuntos difíciles o que involucren la dimensión político constitucional del Tribunal de Casación (Pizzorusso), y lo cierto es que en definitiva con estos argumentos también están apelando a criterios semejantes o análogos a aquellos que en definitiva se suelen englobar dentro del concepto de interés general o casacional ${ }^{28}$. Para ambos autores las secciones o salas (de apoyo) que se hacen cargo de los asuntos rutinarios o de legalidad ordinaria o de fácil resolución se encuentran jerárquicamente por debajo de la Corte o Tribunal Supremo en sentido estricto, con lo cual la sección o sala se constituye en una suerte de tribunal que se halla en un peldaño anterior.

La propuesta de Pizzorusso - como se ha dicho- se funda sobre la base de atribuir una función eminentemente político-constitucional a la Casación, consistente en concurrir con el poder legislativo al afianzamiento del Derecho objetivo nacional ${ }^{29}$. Al respecto mantiene que la diversidad de funciones que se encomienda a la Corte y la sobrecarga de asuntos atentan contra la función propia de la casación reconocida ya en el mismo art. 65 de la Ley sobre Ordenamiento Judicial italiano, y por eso propone una organización interna de la casación concordante con un sistema de selección interno de asuntos que permita la disminución de carga de trabajo para posibilitar al mismo tiempo el contenido político-constitucional de la (casación) Corte Suprema ${ }^{30}$. La propuesta de Pizzorusso recae sobre las medidas que inci-

22 Cappelletti (1965) pp. 111-122.

23 Pizzorusso (1992) pp. 181-197.

24 Nieva (2010) pp. 31 y ss.

25 López (2010) pp. 123 y ss., aunque con matices de relieve.

26 WheELer (2004) pp. 254-255.

27 Nieva (2010) pp. 31-32.

28 Así expresamente Cappelletti (1965) p. 118.

29 Vid. Pizzorusso (1992) pp. 181-197.

30 Pizzorusso (1992) p. 184. Apunta al respecto «Ha sido ahora frecuentemente observado que un órgano lleno y sobrecargado, como es actualmente la Corte de casación, resulta poco adecuado para desarrollar las funciones de una 'Corte Suprema', es decir, de un juez que adopte en forma jurisdiccional decisiones las cuales tienen por objetivo, más allá de la tutela de los particulares intereses comprometidos en los casos concretos que ella examina, la realización de las finalidades indicadas por el art. 65 del Ordenamiento Judicial según el cual la Corte 'asegura la exacta observancia y la uniforme interpretación de la ley, la unidad del Derecho objetivo nacional, el respeto de los límites de las diversas jurisdicciones'. En otros términos, esta contraposición es tal vez eficazmente expresada señalándose que como función de una Corte suprema no sea tanto aquello de resolver li- 
den entonces sobre la organización judicial, aun cuando aquella aparezca individualmente vinculada a medidas legales que contemplen un sistema de selección interno de aplicación de procedimientos o cauces preferenciales armónicos con aquella. En lo que nos interesa, el autor italiano ${ }^{31}$ propone el establecimiento de una modificación organizacional interna de la Casación que parece estar suponiendo un sistema de selección interno que se resuelve en la diversificación de procedimientos y de instancias orgánicas de la Casación (que deba conocer y resolver), aun cuando aquello podría lograrse también con el traspaso de la competencia de aquellos asuntos de legalidad ordinaria o de solución rápida o fácil para ante órganos jurisdiccionales distintos de la Corte de casación, quedando para este solamente aquellos asuntos que importen cuestiones vinculadas a su cometido político-constitucional.

El legislador italiano ha acogido una modalidad muy semejante a la explicada con la reforma de 2009 al Código Procesal Civil italiano ${ }^{32}$, en virtud de la cual se crea una «apposita sezione», denominada "sezione filtro" a la que le corresponde el examen preliminar de todos los asuntos planteados con el fin de determinar si corresponde la aplicación de un rito procedimental simplificado o bien el procedimiento con audiencia pública. Ese examen supone la intervención inicial de un magistrado relator nombrado con el fin de que examine la concurrencia de los supuestos que permita discernir a qué procedimiento y ante que sección se remitirá el asunto, conforme la posible configuración de hipótesis de inadmisibilidad o, incluso, de hipótesis de rechazo o estimación que no requieren de estudio exhaustivo ${ }^{33}$.

Por otra parte, como se ha apuntado, propuestas análogas a las anteriores - mutatis mutandi- han tenido lugar en USA ${ }^{34}$ : en los años setentas (1972) la denominada Freund Commission (Study Group on the Case Load of the Supreme Court) proponía la creación de un nuevo nivel judicial en el entramado judicial estadounidense, ubicado entre la Corte Suprema Federal y las Cortes de Apelaciones intermedias. Se planteaba así una Corte Nacional de Apelación con siete miembros permanentes. Esta Corte iba seleccionar los asuntos que iba a referir a la Corte Suprema, y junto con ello iba a tener el poder de resolver aquellos casos que decidía no remitir a la Corte Suprema y hubiera, no obstante, jurisprudencia contradictoria proveniente de distintos distritos. Posteriormente (en los años noventas) se han planteado variantes de esta propuesta. Todas ellas se han sostenido en el supuesto de que la Corte Suprema no sería capaz de hacerse cargo de todos los asuntos en donde existe conflicto entre los distintos circuitos por la producción de jurisprudencia contradictoria. Con todo, estas propuestas no han prosperado.

Para la situación chilena opciones como las que se explican debieran suponer un reparto de funciones siempre bien articulado sobre criterios de interés casacional que, en lugar de determinar o incidir en el acceso a la casación, determinen única y precisamente el acceso a la Corte Suprema, vale decir, determinen solamente la competencia funcional de la casación. De esta manera el control sobre la admisión y sobre el reparto habría de correspon-

tigios entre las partes, cuanto aquel de concurrir con el legislador al afianzamiento del Derecho nacional (y por lo tanto al cumplimiento de una función más político-constitucional que procesal)».

31 Pizzorusso (1992) pp. 185-186.

32 En adelante CPCi.

33 Vid. Amoroso (2012) pp. 530-531.

34 Wheeler (2004) pp. 254-255. 
der a los tribunales superiores (o bien a una sala filtro), los que decidirían retener y conocer aquellos asuntos en donde existe jurisprudencia uniforme, la que deberá ser aplicable al caso y que, en el supuesto de ser compartida por el tribunal superior, habrá de resultar en la estimación o desestimación correspondiente. Por el contrario, en las hipótesis en que parezca discutible la jurisprudencia interpretativa o superada por la misma argumentación recursiva o esta sea inexistente, el tribunal superior debería proceder a conceder el recurso para ante la Corte Suprema. Así, se armonizan adecuadamente todos los valores de la casación y no se incurre en el error de dotar de vinculación jurídica estricta a la jurisprudencia ${ }^{35}$.

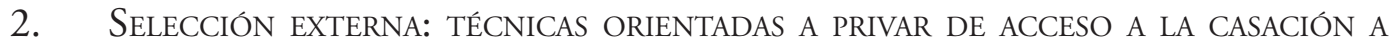 UN CONJUNTO DE ASUNTOS}

Tal como se ha señalado, el tratamiento, en nuestro medio, del problema de la selección externa se ha visto limitado a las referencias más o menos precisas al denominado writ of certiorari ${ }^{36-37}$, entendido como una decisión que responde a una técnica procesal dispuesta para la selección discrecional ${ }^{38}$ de asuntos por parte de la Corte Suprema, y en virtud de la cual se determinan cuáles de aquellos ingresan al conocimiento y decisión de la propia Corte, y que operaría como una potestad de selección que -en tanto discrecional- no requiere de justificación en un criterio de decisión preciso o el mismo puede quedar omitido, lo cual por lo demás es consistente con la inexistencia de una tasación normativa eficaz de cuáles son esos criterios de selección legítimos y verificables.

Una modalidad de selección de recursos ante la Corte Suprema como la indicada es la que se encuentra en vigor en USA. Las normas jurídicas contenidas en el Judicial Code de USA, capítulo 81, secciones 1251 a 1259 , regulan la función y la competencia de la Corte Suprema, pero no establecen ningún concepto definitorio de esta potestad ni menos criterios normativos para la concesión del certiorari. Ha sido la propia Corte la que en las Reglas que se ha dado (Reglas de la Corte Suprema federal) ofrece algún marco regulatorio. Específicamente -en lo que nos interesa- la regla 10 de las Reglas de la Corte indica primero que el acceso a la Corte no es un derecho o garantía procesal de rango legal de los litigantes. En segundo término, y en sintonía con lo anterior, si bien se refieren unos supuestos orientadores de cuándo la Corte podría conceder el certiorari, al mismo tiempo se encarga de señalar que tales criterios no limitan el poder discrecional de selección. De esta manera el acceso a la Corte no es un derecho para las partes que litigan (ni siquiera de configuración legal) y precisamente por eso es posible que la Corte seleccione discrecionalmente.

\footnotetext{
35 Vid. López (2010) pp. 124-126.

36 Para entender bien estos tipos de controles de acceso discrecionales hace falta tener en cuenta la función de las Cortes Supremas en esos modelos, y los fundamentos de su intervención jurisdiccional. Vid. las interesantes cuestiones que se exponen por GoodNow (1891), pp. 493-536, con apuntes históricos, y actualmente Bankowski, Maccormick y Marshall (1997) pp. 315-354; Summers (1997) pp. 355-406; Wheeler (2004) pp. 237-270; Le Sueur (2004) pp. 271-292; Brenner y Whitmeyer (2009) 196 pp.

37 En nuestro medio sobre el particular y con sentido crítico que compartimos, vid. Delgado (2010) pp. 361-375.

$38 \mathrm{Al}$ respecto la doctrina estadounidense no duda en calificar el modelo de selección de writ of certiorari aplicable en USA como basado en la decisión discrecional de la propia Corte. Vid. Linzer (1979), pp. 1228-1305; Ahumada (1994), pp. 109-136; Harnett (2000), pp. 1644-1738; Scott (2006) pp. 191-207; Hernández (2008) pp. 78-88; Brenner y Whitmeyer (2009) 196 pp.; Sommer (2010) pp. 316-341.
} 
Nótese, sin embargo, que la regla 10 señala como criterios de selección orientadores los siguientes: (a) la existencia de decisiones contradictorias provenientes de distintas corte de apelaciones federales o de diversos tribunales estatales, y que se refieran a cuestiones de Derecho federal; (b) la existencia de una decisión de una corte de apelaciones federal que suponga la infracción al procedimiento judicial regularmente aceptado; (c) la existencia de una decisión de una corte de apelaciones federal o de un tribunal estatal sobre Derecho federal y en oposición a la decisiones precedentes de la Corte Suprema, y (d) la existencia de decisión de una corte de apelaciones federal o de un tribunal estatal, sobre una cuestión de Derecho federal respecto de la cual la Corte Suprema todavía no se ha pronunciado pero debería hacerlo en función de la importancia que reviste el asunto.

La eficacia de los criterios indicados, y en consecuencia la capacidad de orientación de estos, sin embargo, es muy baja ${ }^{39}$. Así cabría inferir además por los poquísimos asuntos a los que año a año se les concede el certiorari, como por la paulatina disminución en el último tiempo de la cantidad de asuntos seleccionados no obstante el incremento significativo de casos y resoluciones susceptibles de acceder a la Corte ${ }^{40}$. Por otra parte llama la atención cómo los estudios académicos, que intentan levantar teorías que expliquen cuáles sean las variables que justifican la selección de asuntos, se centran en el estudio de elementos y consideraciones propias de la evaluación estratégicas en el manejo (administración) de los volúmenes de carga de trabajo y la selección de qué cosas merecen atención, ciertamente bien alejados de criterios jurídicos claramente preestablecidos ${ }^{41}$.

Se dice en la línea apuntada que la existencia de decisiones entre distintos tribunales y cortes o la separación de estos de un precedente de la Corte Suprema no asegura la intervención de esta. Aquello va a depender de la importancia del asunto de Derecho federal, cuestión que se evalúa de forma bastante libre por la misma Corte ${ }^{42}$. Pero tampoco la importancia del asunto de Derecho federal asegura la intervención de la Corte, puesto que esta exigiría además que el problema que se plantea tenga un cierto filtrado previo en pronunciamientos anteriores provenientes de diversas cortes o tribunales, con lo cual se exigiría una determinada maduración de la cuestión en la que podría recaer la atención de la Corte. Y aun en este caso, al final se acaba reconociendo que en último término las áreas de interés o preferencia específicos de los miembros de la Corte es una variable que explicaría por qué se escogen más casos de una materia que de otras, con independencia de su atendibilidad ${ }^{43}$.

A todo lo anterior, habría que añadirle todas las presuntas o reales conductas estratégicas de los miembros de la Corte, como puede llegar a ser -entre otras- el denominado defensive denial, consistente en la decisión que aquel adopta en orden denegarle el certiorari

39 LinZer (1979), pp. 1228-1305; Ahumada (1994), pp. 109-136; Harnett (2000), pp. 1644-1738; ScotT (2006) pp. 191-207; Hernández (2008) pp. 78-88; Brenner y Whitmeyer (2009) 196 pp.; Sommer (2010) pp. 316-341.

${ }^{40}$ Problema ampliamente estudiado y documentado. Así, por ejemplo, Wheeler (2004), pp. 237-270; Scott (2006), pp. 191-207; POSNER (2011), pp. 297 y ss.

${ }^{41}$ Así Harnett (2000), pp. 1726-1730, sugiere que el poder de selección que tiene la Corte Suprema federal en Estados Unidos responda más a un poder de naturaleza administrativa que propiamente jurisdiccional.

42 Harnett (2000) pp. 1718 y ss. También Ahumada (1994) pp. 109-136.

43 SCott (2006) pp. 191-207; Brenner y Whitmeyer (2009) 196 pp.; Sommer (2010) pp. 316-341. 
a un asunto determinado únicamente porque vislumbra que, de concedérselo, la decisión de fondo de la Corte sería adversa a sus preferencias ${ }^{44}$.

En las circunstancias apuntadas resulta muy difícil hacer una caracterización de un sistema como este conforme reglas claras que aseguren la juridicidad de la selección que realiza la Corte, menos cuando esta tampoco soporta el deber de justificar la denegación del certiorari solicitado.

Por otra parte, si se atiende a la experiencia de la Corte Suprema federal de USA, habría que reflexionar antes sobre los agudos apuntes de Posner ${ }^{45}$ sobre el volumen de cuestiones conocidas por aquel y poner aquello en relación con los fines de la casación o de cualquier recurso extraordinario, y cómo además esta relación puede incidir en la propia concepción de Corte Suprema que se tenga. Las consideraciones que hace el autor estadounidense marcan una brecha insalvable: la discrecionalidad en la selección de asuntos le ha permitido a la Corte Suprema en USA tener su propia agenda política y dedicarse a determinados asuntos y posponer otros, con independencia de su atendibilidad.

Posner $^{46}$ señala al respecto: "Comienzo con un factor al que no se le ha prestado la debida atención en las discusiones acerca de la politización del Tribunal Supremo: el extraordinario crecimiento de la ratio de sentencia de los tribunales de instancia en relación con las del Tribunal Supremo. El Supremo ya no puede controlar a los tribunales de instancia por medio de resoluciones estrictas, caso a caso, que es el método sostenido, gradual, del common law. Debe actuar necesariamente como legislador. En el 2003, los tribunales de apelación federales decidieron 59.396 casos, que han de ser comparados con los solo 3.753 que fueron decididos en 1960. Los tribunales estatales de última instancia decidieron más de 25.000 casos en 2002, de los cuales aquellos que versaban sobre un problema federal era un porcentaje desconocido, pero muy probablemente sustancial, a juzgar por el hecho de que el 13 por 100 de las decisiones del Tribunal Supremo del estado a finales de los años sesenta -cuando el derecho constitucional no era todavía ubicuo- se refería a los derechos constitucionales de los acusados en un proceso penal. Los tribunales estatales de nivel intermedio resolvieron más de 130.000 casos en el año 2003. Lo que está sin determinar es cuántas de tales decisiones eran decisiones finales que planteaban problemas de derecho federal y que, por tanto, eran revisables ante el Tribunal Supremo de los Estados Unidos. No podemos entonces decir cuántos de los casos que podrían haber sido revisados por el Tribunal Supremo fueron decididos por los tribunales estatales en cada período, para poder hacer así el cálculo del porcentaje de casos en los que el Supremo concedió tal revisión [certiorari]. Pero uno puede comparar el porcentaje de casos de los tribunales federales en los que el Supremo concedió tal revisión en el año 2004 -0,011 por 100 (64: 56,396)- con el correspondiente porcentaje en el año 1960 -1.6 por 100 (60: 3,753). La comparación nos permite ver que en 1960 el Supremo revisó, en términos relativos, casi quince veces más el número de casos procedentes de los tribunales estatales que los que había revisado en 2004».

\footnotetext{
44 SCott (2006) pp. 191-207; Brenner y Whitmeyer (2009) 196 pp.; Sommer (2010) pp. 316-341.

45 Posner (2011) pp. 297 y ss.

46 Posner (2011) pp. 297-298.
} 
"Con seguridad, muchos de los casos que vieron su fin en los tribunales de apelación federales no son ni siquiera remotamente candidatos plausibles para posterior revisión y ello en la medida en que o bien devinieron firmes, o fueron abandonados, o rechazados debido a errores jurisdiccionales obvios. Si centramos nuestra atención en los casos que la oficina administrativa de los tribunales de los Estados Unidos entiende que han llegado a su fin 'en virtud a sus propios méritos' o (la correspondiente, aunque no idéntica clasificación de 1959) 'tras audición o presentación', las cifras de 56.396 y 3.753 del párrafo anterior se reducen a 27.009 y a 2.705 y este ajuste cambia el porcentaje de las decisiones del tribunal de apelación federal que son revisadas por el Tribunal Supremo y que van del 0.013 y 1,7 por 100 en 2004 y 1960, respectivamente, a un 0,27 por 100 y un 2,4 por 100. Sin embargo la diferencia no deja de sorprender: el Supremo decidió en 1960, en términos relativos al menos nueve veces el número de casos federales que decidió en 2004».

El autor ${ }^{47}$ un poco más adelante concluye que los casos que la Corte decide disminuyen en relación con el número total de casos de los tribunales inferiores en los que se plantean cuestiones federales, y por ello afirma que parece que la Corte estuviera dejando «en manos de los tribunales inferiores amplias franjas del derecho federal». Y paralela y simultáneamente se estaría verificando una progresiva preocupación preferente de la Corte por los asuntos constitucionales ${ }^{48}$ más polémicos y que en razón de su particular naturaleza sería un ámbito de decisión en donde se puede ejercer una discrecionalidad comparable con la del poder legislativo ${ }^{49-50}$.

Según lo que se ha apuntado se puede inferir además que un sistema de selección discrecional acabaría propiciando una retirada del control o defensa del Derecho objetivo, por una parte, pero asimismo un sistema de esta especie termina favoreciendo un comportamiento basado en criterios de oportunidad política de la Corte Suprema, en tanto le consiente a este tener su propia agenda en virtud de la cual acaba seleccionando un minúsculo segmento de asuntos que representan a su vez una minúscula parte del total de problemas interpretativos que aquejan a un Ordenamiento Jurídico, con una bastísima producción de normas jurídicas, aplicadas a unas complejas y dinámicas relaciones jurídico materiales en los más diversos ámbitos. En otras palabras, un sistema como este no logra hacer una defensa efectiva del Derecho objetivo, y tampoco consigue la unificación de la interpretación judicial eficiente sino en una parcela reducida del Derecho, y a la par se puede estar alentado un comportamiento fuertemente politizado del Tribunal Supremo, en donde se atienda

\footnotetext{
47 Posner (2011) p. 300.

48 Posner (2011) p. 300, sostiene que «[c]uanto más preocupado se ve al Supremo con los casos constitucionales polémicos, más parece un órgano político con una discrecionalidad de amplitud comparable a la del legislativo. Como la Constitución federal es difícil de enmendar, el Supremo ejerce, por lo general, más poder cuando se ocupa de resolver casos constitucionales que cuando resuelve casos legislativos. Es más, una Constitución suele ocuparse de los temas fundamentales, asuntos que suscitan mayores pasiones que los asuntos legislativos, y la emoción puede llevar a los jueces a desviarse de un análisis técnico desapasionado. Y es que se trata de asuntos políticos: asuntos acerca del gobierno de la nación, de los valores políticos, de los derechos políticos y del poder político».

49 Summers (1997) pp. 371-372, describe sobre este punto un panorama semejante.

50 Nieva (2010) pp. 50-51, con unos argumentos semejantes a las observaciones que realiza Posner mantiene la insuficiencia del modelo writ of certiorari para responder a la finalidad de la nomofilaquia y del ius constitutionis y ius litigatoris.
} 
a criterios de oportunidad o conveniencia opacos en la selección de asuntos que distan de la ecuanimidad jurisdiccional, y con carencia de controles eficientes ${ }^{51}$.

Para el caso del sistema jurídico chileno, las reflexiones sobre la introducción de formas de selección como el writ of certiorari habrían de tener en cuenta la opinión del Tribunal Constitucional, que ha fijado una posición sobre un problema equivalente en la conocida Sentencia de 1 de febrero de 1995, rol 20552. En ella esta judicatura se pronunció -en control de constitucionalidad preventivo- sobre la propuesta de establecimiento de una potestad (de la Corte Suprema) para el rechazo in limine del recurso (norma de selección encubierta), por carencia de relevancia jurídica para la adecuada interpretación y aplicación del Derecho. El propósito era que la infracción in iudicando solo pudiese prosperar como motivo del recurso cuando se planteara una cuestión relevante referidos a problemas interpretativos y aplicativos aprovechables para la generación de doctrina o jurisprudencia. Tal potestad de la Corte Suprema que se pretendía introducir en el artículo 782 del CPC, el mencionado Tribunal Constitucional no dudó en calificarla de abiertamente inconstitucional -entre otras razones- por su manifiesta ambigüedad y por someter por completo la pretensión recursiva al interés público de unificación jurisprudencial y doctrinal, desentendiéndose de la cuestión planteada por el recurrente, lo cual en definitiva suponía una infracción a la igualdad ante la ley (19.2 Constitución) tanto como al denominado principio orgánico de la inexcusabilidad constitucionalmente reconocido en el art. $76(73)^{53}$. En fin, también consideró que el otorgamiento de un poder completamente indeterminado y por lo tanto discrecional para «rechazar» (inadmitir, en realidad) el recurso violenta además el art. 77 (74) que establece que las atribuciones de los tribunales de justicia han de venir determinadas por una Ley Orgánica, con lo cual tal determinación de atribuciones por el legislador orgánico quedaba burlada con la concesión de poderes discrecionales que la norma hacía, la que en definitiva -como se ha dicho- fue declarada inconstitucional por estas razones.

Cabe apuntar, sin embargo, que esta forma de selección externa referida no es la única posibilidad de configuración legal de filtro de acceso a la casación. Este puede adoptar caracteres menos extremos y, en consecuencia, más armónicos con el modelo jurídico chileno. En este ámbito, conocido es el uso de formas de selección como la concesión del recurso por juez inferior vinculado a supuestos normativos, o también los sistemas que utilizan criterios normativos de selección como la summa cassationis o el interés casacional.

\subsection{La permisión del recurso por el tribunal inferior vinculada a supuestos normativos en el modelo alemán de selección de asuntos}

Hasta la entrada en vigor de la reforma legal de 2001 Alemania mantenía un sistema mixto de selección de asuntos ante el Tribunal Supremo federal que se basaba en la cuantía

\footnotetext{
51 Conviene recordar que la gran diferencia entre el poder que ejercen los órganos jurisdiccionales del poder como el que corresponde al legislador tiene que ver con el ejercicio de una potestad (con sumisión a) fuertemente condicionada por normas preexistentes: de allí la notable diferencia de cómo deliberan los jueces a cómo deliberan los políticos en el seno de los órganos legislativos, los cuales llevan a cabo una deliberación en general no condicionada o débilmente limitada desde un punto de vista normativo.

52 Del Río (2013) pp. 282-283.

53 Vid. también la opinión de Atria (2005) pp. 276-278.
} 
del asunto en el que se planteaba el recurso de revisión (casación). Si la cuantía no superaba una cantidad determinada, el recurso quedaba sometido a la previa permisión del propio tribunal de instancia que dictaba la resolución, en la que se reconocía el carácter de recurrible en tanto se entendiese que el asunto revestía un interés o importancia pública general o que había jurisprudencia divergente del Tribunal Supremo. En cambio los asuntos de una cuantía elevada podían acceder al Tribunal Supremo federal directamente, el que no obstante podía desestimar el conocimiento de fondo si el caso no tenía interés o importancia pública general, aun cuando la Corte Constitucional alemana declaró que debía conocer los asuntos en que existía un error determinado en el enjuiciamiento recurrido ${ }^{54}$. En esta forma de selección se constató que los tribunales de apelación que tenían el poder de pronunciarse de oficio en la propia resolución que dictaban acerca del carácter recurrible de la misma mantenían una conducta extremadamente restrictiva, declarando infrecuentemente el carácter recurrible de aquella en los asuntos de cuantía menor.

La reforma de 2001 opta por la eliminación del criterio de la cuantía y somete parejamente a todos los asuntos al sistema de permisión del recurso por parte del tribunal de instancia que junto con decidir sobre el fondo determina el carácter recurrible o no de su propia decisión ${ }^{55}$. Con todo, un sistema como este está lejos de establecer un sistema de selección discrecional, en donde la propia Corte que dicta la resolución pueda a su arbitrio permitir el recurso, declarándola recurrible. La Ordenanza alemana ha previsto los supuestos normativos en que aquella concesión o autorización deba darse y, por otra parte, ha previsto al mismo tiempo un recurso de queja por recurso denegado para ante el Tribunal Supremo federal, con el cual se puede impugnar la denegación del mismo. En otras palabras, un sistema como este prevé dos garantías contra el arbitrio o la pura decisión de oportunidad o conveniencia en la denegación del acceso al recurso de casación ante el Tribunal Supremo ${ }^{56}$.

Como se ha dicho el sistema consagra los supuestos que determinan la permisión del recurso de casación. Hasta antes de la reforma de 2001 la Corte de instancia únicamente adoptaba su decisión con el criterio normativo de la importancia pública general que revestía o no el asunto concreto (además de la existencia de jurisprudencia divergente). Este se consideraba extremadamente ambiguo y en consecuencia consentía a las Cortes y al propio Tribunal Supremo federal un grado significativo de discrecionalidad para denegar el recurso de casación o decidir no entrar al fondo ${ }^{57}$. Por esa razón la reforma de 2001 habría decidido vincular a las Cortes a supuestos normativos más precisos y menos vagos, por la vía de consagrar tres hipótesis claras en el $\$ 543$ subsecc. $2^{\circ}$ de la Ordenanza: a) la importancia fundamental que revista el asunto, b) la necesidad de desarrollo del Derecho, y c) el aseguramiento de la unificación jurisprudencial.

\footnotetext{
54 Habscheid (1994) pp. 126-127; Murray y Stürner (2004) pp. 386-399; Walter (2005) pp. 81 y ss; GotTWald (2008) pp. 88 y ss.; Pérez y Ortiz (2005) p. 128.

55 Murray y StÜrner (2004) p. 387; Walter (2005) pp. 81 y ss.

56 Walter (2005) pp. 81 y ss; Gottwald (2008) pp. 88 y ss.; Pérez y Ortiz (2005) pp. 128-130.

57 GotTWald (2008) p. 90.
} 
A estos criterios normativos de selección en su aplicación se les ha concedido un significado específico ${ }^{58}$. En cuanto a la importancia fundamental del asunto, se entiende que esta concurre cuando el asunto envuelve el interés público de una manera especialmente intensa, o en aquellos supuestos en donde esté envuelto el Derecho comunitario, o en casos en que se planteen cuestiones nuevas no resueltas con leyes anteriores.

Tocante al desarrollo de la ley, se ha dicho que este criterio concurre en tanto haya necesidad de desarrollo o perfeccionamiento de la ley en los asuntos que plantean situaciones no precisamente previstas o reguladas en la ley y requieran entonces del desarrollo de principios interpretativos o de integración de lagunas legales. Gottwald ${ }^{59}$ sostiene que el desarrollo de la ley a través de la interpretación está impuesta en áreas en donde el Ordenamiento es insuficiente (incompleto) o no refleja el continuo desarrollo de la realidad.

Respecto al interés en el aseguramiento de la unificación jurisprudencial, se afirma que este supuesto se resuelve en la necesidad de defender la jurisprudencia consolidada en contra de la tendencia de las Cortes inferiores de hacer distinciones para separarse de aquella. Concurre este supuesto de aseguramiento de la homogeneidad de la jurisprudencia frente a la decisión que se desvía arbitrariamente de un precedente válido.

En el sistema alemán también se exige que el error de Derecho denunciado sea de una especial entidad o posea una especial relevancia. No basta en principio con la existencia de un error jurídico en la sentencia impugnada ${ }^{60}$. Se requiere al mismo tiempo que ella implique la violación de una norma constitucional o que haya un riesgo de que el error jurídico que se denuncia se propague a futuras decisiones de la misma u otras cortes que le sigan (y nos encontremos con un error jurídico sintomático capaz de propagarse). Con todo, en la práctica el error en la aplicación de la ley material suele acceder a control del Tribunal Supremo aun fuera de estos casos porque se entiende que si aquel error es evidente acaba infringiendo la proscripción de la arbitrariedad ${ }^{61}$ o se le subsume en el supuesto del peligro de repetición e imitación, lo cual en definitiva le permite el acceso a un número significativo de casos al Tribunal Supremo federal, con lo cual puede concluirse que el sistema no omite la consideración del interés subjetivo del recurrente (el ius litigatoris) ${ }^{62}$, haciendo primar absolutamente los intereses públicos.

Para dimensionar exactamente con qué garantía de regularidad y respeto a criterios normativos (razonabilidad) puede estar funcionando un sistema de selección resulta interesante atender a los datos estadísticos. Así, se ha señalado ${ }^{63}$ que el Tribunal Supremo alemán resuelve cada año entre 4.000 y 5.000 asuntos civiles, lo cual permitiría la mantención de la uniformidad jurisprudencial y la tutela jurídica de los particulares. Ciertamente, este

\footnotetext{
58 Cabe observar aquí que Murray y STÜRner (2004) pp. 387-390, si bien afirman que el sistema alemán se basaría en una selección discrecional, no obstante, al mismo tiempo refieren un comportamiento anterior al año 2001, en orden a interpretar los supuestos normativos de revisión, como excesivamente restrictivos.

59 GotTwald (2008) p. 91.

60 Murray y StÜrner (2004) pp. 390-392.

61 WaLter (2001) pp. 740-741, sobre el derecho a la previsibilidad en el desarrollo del proceso y el principio de igualdad vinculados a la proscripción de la arbitrariedad en el proceso civil alemán.

62 Gottwald (2008) pp. 92-93.

63 Gottwald (2008) p. 106.
} 
dato cuantitativo contrasta con la estadística de la Corte Suprema de USA, la que muestra que esta no llega en los últimos años judiciales a los 100 asuntos resueltos en total ${ }^{64}$.

\subsection{La summa cassationis y el interés casacional}

La summa cassationis es otra de esas técnicas procesales de selección externa ampliamente conocida y utilizada para racionalizar la carga de trabajo de la casación. La misma, sin embargo, no ha estado exenta de críticas, al menos en su utilización más obvia, como criterio de selección que niega acceso a la casación sin más. En efecto, y aun cuando se mantenga que no existe condicionamiento constitucional impuesto al legislador para establecer unos recursos específicos en el proceso civil con un determinado régimen de acceso -semejante al derecho al recurso en el proceso penal- lo cierto es que de todos modos se ha criticado la técnica de la summa cassationis como filtro o criterio de selección a la casación. Primero, porque su aplicación podría dejar áreas del Derecho objetivo -de su aplicación- sin control casacional, cuando está referido a materias que dan lugar a litigiosidad de baja o mediana cuantía, la que no obstante puede poseer significativa trascendencia social y para los mismos justiciables. Segundo, porque la aplicación de un criterio de esta especie puede ser manipulada por las partes que pueden plantear demandas sin cuantía o con cuantías inadecuadas, lo cual obliga a adoptar una serie de resguardos normativos que aseguren su regularidad y objetividad. Tercero, la summa cassationis tampoco potencia por sí misma la unificación jurisprudencial, sino en principio lo contrario, en tanto tiende a propiciar la existencia de una jurisprudencia uniforme únicamente para los asuntos de cuantía superior que sí acceden a la casación y consiente en paralelo la divergencia jurisprudencial para los mismos asuntos y normas que llegan únicamente a las Cortes de segunda instancia por no alcanzar la cuantía de acceso a la casación. Y tal circunstancia genera desigualdad de trato de situaciones jurídicas perfectamente equivalentes, y ello sí puede tener trascendencia constitucional ${ }^{65}$.

Con todo, el uso de la summa cassationis puede ser una técnica aprovechable si se le pone en relación con el interés casacional, al funcionar en ese supuesto como una vía de acceso directo que excluya la aplicación del requisito de admisibilidad del mismo interés casacional -y no como un filtro para el acceso-. Entonces aquellos asuntos que no alcancen una cuantía determinada pueden de todos modos acceder a la casación si revisten interés público en cualquiera de sus hipótesis que justifique la intervención casacional a su respecto. La combinación de estas reglas evita las consecuencias criticadas de la summa cassationis antes consignadas. Esta fue a nuestro juicio una de las ideas esenciales que quiso consagrar el legislador español en el art. 477 LEC, aunque con posterioridad a su entrada en vigor el Tribunal Supremo español haya hecho una interpretación diversa que le privó en buena medida de este sentido ${ }^{66}$.

Por lo expuesto, no sería descartable el criterio de la summa cassationis para una futura reforma, pero siempre que su uso fuese en el segundo sentido apuntado y que operase como regla que en definitiva relevase -para casos de cuantías elevadas- del requisito del in-

\footnotetext{
64 WheELER (2004) p. 257.

65 Vid. Serra (1993) pp. 235-236; López (2002) pp. 48-49; Ortells (2010) pp. 35-36; Gottwald (2008) p. 89.

66 Vid. López (2002) passim; Blasco (2002) passim; Ortells (2010) passim; Bonet (2006) pp. 387-400.
} 
terés casacional, con lo cual no operaría como una forma de privación de acceso, sino como vía de acceso directo, y de este modo se superarían además las críticas que se han formulado con respecto a su uso.

Ha de tenerse en cuenta, sin embargo, que la utilización combinada de los criterios de la cuantía del asunto y del interés casacional solo podrá funcionar adecuadamente en tanto se haga un cuidadoso y preciso diseño de los criterios que configuran dicho interés, destinado a evitar que el Tribunal o Corte acabe haciendo una aplicación restrictiva del interés casacional en los asuntos que no ingresan por la cuantía a casación.

\subsection{El interés público o casacional}

Por su parte, el interés público o interés casacional en relación con el establecimiento de filtros de acceso se suele construir con base en el predominio de la finalidad de la unificación jurisprudencial. Y aun cuando aquello no suponga la exclusión de la finalidad de la nomofilaquia, esto es, la defensa del Derecho objetivo, esta se reconoce como finalidad subordinada y limitada por la primera. La conclusión precedente es innegable y parece ser el costo que impone la necesidad de racionalización de la casación. Sin embargo, la limitación de la defensa del Derecho objetivo varía según como se configure el interés público o casacional como filtro de acceso, lo cual depende desde luego de cuán severo sea en tanto filtro, en función en último término de la carga deseable para la casación dentro de un ordenamiento jurídico.

En concreto, el interés casacional en nuestra opinión debiera ser elaborado sobre la base de los tres criterios siguientes: la 1) oposición o contradicción jurisprudencial, 2) la necesidad de creación de jurisprudencia cuando esta falta y 3) la necesidad de superar la jurisprudencia interpretativa-aplicativa en vigor. Por lo anterior es que debiera entenderse que existe interés casacional y se justifica el acceso casacional en caso que se impugne una resolución en oposición a la jurisprudencia consolidada de la Corte Suprema (CS), o en caso que exista contradicción jurisprudencial entre sentencias emanadas de las Cortes de Apelaciones cuando falta jurisprudencia de la CS, o se impugne una resolución que resuelva un asunto que debía ser resuelto conforme una norma jurídica nueva respecto de la cual no exista jurisprudencia aplicable, o, en fin, se impugne una resolución que no obstante conformarse a la jurisprudencia unificada de la CS se justifique a su respecto la necesidad de superarla, con base en una interpretación normativa avanzada por el mismo recurrente.

Los primeros supuestos responden a los que están previstos en el art. 477 LEC española. El último en cambio no está previsto en ella, pues en aquel modelo legal la evolución jurisprudencial no puede ser promovida por la vía del recurso de casación por las partes. La promoción de dicha evolución viene dada por la jurisprudencia disidente de las Audiencias Provinciales que supera la doctrina del Tribunal Supremo (TS). En el modelo español el cambio y evolución jurisprudencial ha de ser suscitado únicamente por aquellos tribunales que con su jurisprudencia disidente le permitan al TS revisar nuevos antecedentes y su propia doctrina. Esta solución puede ser adecuada en el sistema jurídico institucional y judicial español, pero sospechamos que en el estadio en que se halla el sistema judicial chileno, sumados las condiciones materiales y de medios humanos de operación de la justicia, tal evolución interpretativa de la jurisprudencia no sería a menudo oportunamente realizada 
por las Cortes de Apelaciones (CCAA). Así, en nuestra opinión un sistema como este sin alguna matización de relieve para el caso chileno puede provocar inconvenientes de importancia, ya que creemos que por la tradición jurídica imperante y la permanente situación de urgencia con que se aborda la tarea judicial sea dudoso que las CCAA puedan realmente realizar un examen permanente de las interpretaciones jurídicas en juego en el desarrollo interpretativo dialéctico que debiera verificarse en el proceso, y de ese modo promover la evolución razonada de la jurisprudencia, puesto que aquello implica que las CCAA asuman la exposición a la impugnación de sus resoluciones de fondo precisamente por apartarse de la jurisprudencia de la CS, generándole al mismo tiempo una carga de trabajo «evitable» al máximo Tribunal con solo mantenerse dentro de la línea jurisprudencial previamente sancionada, y todo aquello en el contexto de un poder judicial permeado por las denominadas metas de gestión, que operan como estímulos opuestos al escrutinio sereno y reflexivo de los criterios jurisprudenciales fijados con anterioridad.

Por lo anterior, consideramos que un sistema ajustado a las peculiaridades del ordenamiento jurídico y la realidad institucional chilenas no debe privar a los justiciables de promover la superación-evolución jurisprudencial, para lo cual sería menester prever un requisito de admisibilidad sustitutivo en los supuestos en que no concurra interés casacional por no existir oposición jurisprudencial, en cuyo caso la parte recurrente debería ofrecer un extremo de fundamentación añadido en su recurso, con relación a la necesidad de superación de la doctrina jurisprudencial de la CS, el cual habría de quedar sometido a control en fase de admisibilidad en términos semejantes a lo previsto en el art. $782 \mathrm{CPC}$, en donde la CS pueda inadmitir por la falta de fundamentos o antecedentes nuevos que justifiquen la revisión de la doctrina jurisprudencial. De este modo también en fase de admisibilidad podría declararse la falta de concurrencia del requisito de admisibilidad sustitutivo de la oposición de jurisprudencia sentada por la CS.

Una solución de este tipo es la que actualmente contempla el modelo italiano a partir de la reforma de 2009, y que ha establecido un filtro de admisibilidad del recurso en su art. 360 bis CPCi. En este precepto se consagra como causal de inadmisibilidad que debe ser declarada por la "apposita sezione» (denominada "sezione filtro») la existencia de jurisprudencia de la Corte de casación convergente con la sentencia impugnada-contraria entonces al recurso- no obstante lo cual aquella resulta susceptible de ser superada en tanto los motivos del recurso ofrezcan antecedentes que hagan necesarias una revisión de la jurisprudencia ${ }^{67}$.

\subsection{Un excurso aclaratorio: el interés casacional no es el motivo del recurso ni de la casación}

Conviene en esta parte de los argumentos señalar que el interés casacional no es el motivo del recurso de casación ni el motivo de la casación (anulación), sino únicamente un requisito de admisibilidad. La aclaración precedente es esencial, puesto que se suelen confundir estas dos cuestiones, siendo uno de los errores más extendidos en la comprensión de la discusión que se ha dado en nuestro medio jurídico. Probablemente el mismo Proyecto

67 Sassani (2010) pp. 657-659; Amoroso (2012) pp. 530-531. 
Del Río FerRetti, Carlos —La casación civil: el desafío de la correcta racionalización y iurisprudentia novit curia ..."

de Código Procesal Civil padezca de una confusión de este tipo en los arts. 405 y $409^{68}$. El hecho de que se establezca el mencionado interés con base en la existencia de oposición o contradicción jurisprudencial o en la necesidad de generar jurisprudencia interpretativa o superar la precedente no altera en absoluto la circunstancia de que el motivo de casación (en el fondo) deba seguir siendo la infracción de norma jurídica objetiva -de ley-, y no la misma «infracción» de jurisprudencia ${ }^{69-70}$.

Ello es fácilmente constatable si se observa que en un esquema casacional bien elaborado puede concurrir el interés casacional como requisito de admisibilidad que precisamente determina -junto a otros requisitos- el acceso a casación, pero esto no suponga necesariamente la estimación del recurso y la anulación de la sentencia, pues aquello solo se va a verificar si la Corte considera que se ha infringido una norma de Derecho. Así la sentencia impugnada podría oponerse a la propia jurisprudencia de la Corte, pero ser considerada jurídicamente acertada y ofrecer entonces a la misma Corte una oportunidad para abandonar su doctrina, que viene a ser superada por una nueva y mejor. Esta distinción es imprescindible para aclarar que en un recurso de casación en el fondo (o equivalente) el motivo de casación ha de ser la infracción del Derecho objetivo, y es esa infracción que siendo verificada produce la declaración de nulidad de la sentencia. Y por eso -como se ha dicho- es perfectamente posible que existiendo interés casacional por ser la sentencia impugnada opuesta a la jurisprudencia de la Corte, no obstante, no sea casada, por estimarse que esa jurisprudencia disidente no constituye infracción de Derecho.

Dado lo anterior, el interés casacional entonces es una condición de acceso ${ }^{71}$ que simplemente limita el acceso a la casación en función del motivo; limita la eficacia del motivo del recurso, el cual franquea el acceso a la casación solo en aquellas hipótesis en donde el legislador establezca que exista además interés para que se produzca la intervención casacional. Podríamos decir que el interés casacional es una condición o presupuesto de eficacia del motivo legal del recurso. Vale decir, para que este permita el acceso debe concurrir además el interés casacional. Pero, existiendo, lo que debe afirmarse en el fondo del recurso no es el interés, sino la infracción del Derecho objetivo, que es lo que se denuncia y se preten-

\footnotetext{
68 Del Río (2013) pp. 280-283.

69 Vid. López (2002) pp. 75-76.

70 Debe tenerse en cuenta que el motivo del recurso ha de incardinarse en alguno de los tipos de ouverture à cassation, puesto que su alegación se constituye en la vía de acceso a la casación y delimita el ámbito de conocimiento de la Corte de Casación. El motivo como ouverture à cassation es el relevante para efectos de determinar la admisibilidad del recurso - en fase de control de admisibilidad-, para lo cual la Corte determina si la alegación del error o vicio sería de aquellos que franquea la casación, sin entrar al examen de fundabilidad del mismo, en orden a la determinación de la verificación o no del error o vicio denunciado. La determinación de fondo sobre la concurrencia del error denunciado es la dimensión del motivo que se conoce como motivo de casación (o moyen de cassation) y que debe ser objeto del pronunciamiento de fondo que acoja o rechace el recurso en función de si se entiende o no verificada la denuncia casacional. Vid. Rigaux (1965) pp. 17 y ss; Boré (1988) pp. 564 y ss. y 729 y ss; Jobard-Bachellier y BaChellier (2006) pp. 5 y ss, y pp. 125 y ss; Ferrand (2010) pp. 589-627; Couchez y Lagarde (2014) pp. 483-494.

71 López (2002) p. 120.
} 
de que se censure por la Corte Suprema ${ }^{72-73}$. Por todo lo dicho es que el interés casacional deba ser controlado o examinado en fase de admisibilidad y no en fase de pronunciamiento sobre la fundamentación del recurso sobre la denuncia de casación. Son dos juicios distintos y que no se pueden confundir ${ }^{74}$.

En fin, en un esquema como el que explicamos debe quedar claro que ha de negarse consistentemente la eficacia vinculante a la doctrina jurisprudencial, por lo menos aquella eficacia predicable de las normas jurídicas: por eso mismo es que se consiente -e incluso el sistema requiera- que los tribunales de instancia (y sobre todo los de segunda) en su función interpretativa y aplicativa puedan separarse y superar la doctrina de la Corte Suprema.

Todo esto es esencial para la ordenación sistemática de un recurso de naturaleza casacional o extraordinario, lo cual, no obstante, como ya se ha apuntado, está muy desdibujado en el Proyecto de CPC, sino derechamente distorsionado en esa propuesta legislativa, confundiendo los elementos en juego, con futuras perniciosas consecuencias si no son corregidas.

\subsection{El juicio de oposición o contradicción que ha de realizarse en fase de admisibilidad para determinar la concurrencia del interés público o casacional}

La introducción de técnicas como la del interés público o casacional para la selección racional de asuntos de casación, requiere de una actividad de enjuiciamiento de admisibilidad bien precisa y que se rige por criterios técnicos que conviene tener presente en el análisis. En efecto, el interés casacional cuando se basa en la oposición o contradicción jurisprudencial va a demandar que en fase de admisibilidad la Corte haga un examen que permita realizar un juicio de oposición o contradicción ${ }^{75}$, que deba basarse en una actividad de comparación previa que tendrá que producirse entre la sentencia impugnada y aquellas en donde se fija la doctrina jurisprudencial invocada por el recurrente, apareciendo la que se

72 LÓpez (2002) pp. 139-140.

73 Y por eso es que López (2002) p. 141, señala que «El interés casacional viene a restringir la posibilidad de intervención nomofiláctica del Tribunal Supremo a los supuestos de falta de uniformidad en la aplicación del derecho o de indeterminación del sentido en que deben ser interpretadas las normas recientes. El legislador no ha pretendido que el Tribunal Supremo conozca de todo recurso en el que se alegue una posible infracción de ley, sino únicamente cuando el sentido de la ley -o con mayor amplitud, el Derecho objetivo- resulte incierto por la existencia de contradicciones jurisprudenciales o la simple inexistencia de doctrina jurisprudencial del Tribunal Supremo. Si el recurso debe ser inadmitido cuando falte interés casacional -por ser la sentencia dictada conforme con la doctrina del Tribunal Supremo o no contradictoria con la de otras Audiencias- y, por tanto, el Tribunal Supremo no debe controlar la interpretación de la ley en relación con la impugnación formulada, entendemos que tampoco debe extender su actividad de control, cuando conozca de una impugnación por razón de su interés casacional, a aquellas impugnaciones acumuladas en las que no concurra ese interés. Por lo tanto, solo deberá conocer el Tribunal Supremo de aquellos motivos respecto de los que concurra interés casacional».

Y enseguida concluye Lópz: «Si puede afirmarse que el interés casacional no es moyen de cassation en tanto que su concurrencia no justifica la estimación del recurso, sí que comparte con el motivo de casación su carácter de elemento delimitador del ámbito de conocimiento del Tribunal Supremo, es decir, su carácter de ouverture à cassation».

74 Lópz (2002) pp. 121-138, ofrece una visión precisa y matizada sobre esta cuestión.

75 Romero (2013) pp. 195-206, reflexiona sobre ciertas dificultades análogas a propósito del juicio que debe realizar la Corte Suprema para la determinación de existencia de contradicción jurisprudencial para proceder al conocimiento en pleno, conforme el art. 780 del CPC. 
impugna en oposición a esta última ${ }^{76}$. Y lo cierto es que tal cotejo varía de manera relevante según la denuncia específica de infracción del Derecho de que se trate. Así, la comparación para realizar el juicio de oposición o contradicción será distinta si se denuncia un error en la determinación de existencia o vigencia de una norma jurídica, o bien se invoca la falsa o incorrecta interpretación, o, por último, la falsa o incorrecta aplicación de la norma jurídica.

En el primer supuesto, esto es, el error en la determinación de existencia o vigencia de una norma, la comparación para determinar la oposición será fundamentalmente abstracta, en razón de que incide (la determinación de la existencia o la vigencia de la norma jurídica aplicable) únicamente en la premisa mayor, y se verifica entonces con independencia del supuesto de hecho y de los hechos concretos de la causa. Con lo dicho, el juicio de oposición o contradicción no requerirá que el cotejo se realice entre (dos) sentencias que resuelvan sobre exactamente el mismo supuesto normativo o sobre idénticos hechos concretos. Basta en principio que en una sentencia se haya considerado vigente una norma jurídica y en la otra lo contrario. Inicialmente, casos de esta especie - podría pensarse- que no se producirán sino de manera muy excepcional, pero la realidad del foro demuestra que son más frecuentes de lo que se pueda imaginar y se presentan en todos los órdenes jurisdiccionales. Un caso en nuestro Derecho procesal civil es aquel que se ha producido sobre la vigencia o derogación de las normas sobre regularización de la propiedad raíz contenidas en el DL 2695.

Una situación distinta se produce cuando la denuncia casacional se refiere a un tipo de infracción que se resuelve en la errada interpretación de la norma jurídica, ya que en esa hipótesis frecuentemente se deberá atender no solo a la norma que se interpreta en uno y otro caso, sino exactamente al supuesto normativo que subyace a esa interpretación, cuestión que surge como una necesidad cuando la interpretación de una norma discrimina y matiza tratamientos jurídicos diversos de distintos supuestos comprendidos en aquella. Entonces el cotejo de la sentencia impugnada con aquellas que contienen la doctrina jurisprudencial -juicio de oposición o contradicción- para determinar la existencia de oposición o contradicción debe tener en cuenta aquello. De este modo una aparente oposición o contradicción interpretativa puede no ser tal si las sentencias que colisionan están referidas a supuestos normativos diversos, y es el carácter diverso de los supuestos que se enjuician el que explica la (aparente) oposición interpretativa de una norma. Ahora bien tal distinción debe ser explícita o desprenderse claramente de las mismas sentencias comparadas al efecto. Esto es, la similitud o diferencia de supuestos normativos que han motivado la jurisprudencia ha de ser objetivamente contrastable en función de lo que se denuncia como error interpretativo. En consecuencia la disimilitud de supuestos que explica la diferencia jurisprudencial interpretativa deja de ser tal para pasar a ser un tratamiento diferenciado por la misma diferencia de supuestos.

Por el contrario, tal actividad de cotejo no consiente a nuestro juicio la distinción de ser supuestos disímiles introducida en el mismo control de admisibilidad por la Corte, vale decir, la distinción realizada por la Corte, cuando ella no se desprenda de los mismos términos jurisprudenciales que se comparan. En otro caso, el control de admisibilidad se constituirá en el momento -inadecuado- para armonizar los fallos impugnados, objetiva-

76 Un análisis completo para el caso español, OrTells (2010) pp. 58 y ss. 
mente contradictorios, con la jurisprudencia o doctrina jurisprudencial en vigor, burlándose por completo el sentido del recurso de casación y del interés, por la vía del argumento contingente introducido por medio del control de inadmisibilidad. En este caso, lo correcto es justificar la distinción interpretativa en el pronunciamiento de fondo del recurso, entre otras razones porque de esa manera tal pronunciamiento constituye el afianzamiento de doctrina interpretativa clara, lo que no acontece con la resolución de «inadmisibilidad» por carencia de interés casacional.

Por último, el juicio de oposición para la determinación de interés casacional cuando la infracción de norma jurídica denunciada es la incorrecta (falsa) aplicación de aquella, por errores en la calificación jurídica o subsunción, el cotejo de las sentencias impugnadas en oposición a la doctrina jurisprudencial o contradictorias con otras interpretaciones jurisprudenciales, ineludiblemente impone el deber de atender a los hechos concretos jurídicamente relevantes en cada caso, los que deben ser análogos. Este juicio de oposición es el que demanda una mayor atención ya no solo al supuesto normativo, sino además a los concretos hechos que se enjuician y que pueden estar incidiendo en la calificación jurídica, o que pueden llegar a justificar la diversidad de aquellas, aun cuando se deba sostener que en diversos supuestos prácticos el control de admisibilidad deba venir limitado por el cotejo de dos sentencias y su propia capacidad explicativa y no por el juicio de calificación que mantenga el órgano de control de admisibilidad ${ }^{77}$.

Todos estos problemas deben ser cuidadosamente analizados en cualquier reforma procesal $^{78}$ que pretenda introducir modificaciones análogas a las aquí sugeridas u otras equivalentes, y que debieran recibir un tratamiento esencial en la futura norma que se conciba ${ }^{79}$.

\section{EL PROBLEMA DEL VALOR DE LA JURISPRUDENCIA PARA EL TRIBUNAL DE CASACIÓN Y DEMÁS TRIBUNALES: IURISPRUDENTIA NOVIT CURIA Y EL VALOR DIALÉCTICO (NO NORMATIVO) DE LA JURISPRUDENCIA}

Por último, las consideraciones precedentes cobran sentido si se tiene en cuenta que en nuestro medio deba sostenerse de forma clara que la jurisprudencia no constituye fuente formal del Derecho ${ }^{80}$ y no hace parte del Derecho objetivo ${ }^{81}$. Esta afirmación debe seguir siendo considerada esencialmente correcta en un ordenamiento jurídico de Derecho positivo (legislado), vale decir, puesto por el legislador y aplicado por el poder jurisdiccional. $\mathrm{Y}$ además es una base irrenunciable en cualquier sistema jurídico constitucional moderno dentro de nuestra tradición jurídica, y no como a veces se le quiere presentar, una suerte de afirmación propia del "paleo-positivismo" jurídico completamente superado. La jurisprudencia en lo sustancial interpreta los preceptos jurídicos para poder aplicarlos a los casos

\footnotetext{
77 López (2002) pp. 160 y ss.

78 En nuestro medio el asunto que analizamos ya ha planteado dificultades a propósito de la regulación del recurso de unificación de jurisprudencia laboral. Vid. al respecto el análisis de Delgado (2011), pp. 483-493.

79 Vale la pena reparar en las observaciones que hace OrTells (2010) pp. 47-66, para el caso español.

80 En nuestro medio, Atria (2005) p. 277; Bordalí (2007) p. 527.

81 Para una opinión parcialmente distinta, cfr. Romero (2004) p. 119, y de él mismo (2013) pp. 16-31. También Romero, Aguirrezábal y Baraona (2008) pp. 225-259.
} 
concretos que se le someten. Sin perjuicio de lo anterior, la dogmática moderna no niega en absoluto que al juez le corresponda una función creativa específica, como es aquella de determinar el mandato jurídico concreto aplicable al caso que se deriva del precepto jurídico preexistente (mandato abstracto) y al cual se le atribuye un significado mediante una actividad de interpretación jurídica.

Desde este punto de vista la jurisprudencia que interpreta y aplica el Derecho positivo preexistente no hace parte de ese Derecho, y por tanto no puede decirse que la jurisprudencia sea susceptible de ser «infringida». Infringido puede ser únicamente aquel Derecho positivo preexistente. Las normas positivas que lo integran. Y las infracciones a estas son las únicas que pueden constituir entonces motivos del recurso de casación y ser denunciadas como tales.

Dicho lo anterior, limitadamente podría matizarse lo expuesto, para el supuesto en que se verifica una falta de regulación positiva de situaciones o relaciones jurídicas que al plantearse como conflictos de relevancia jurídica y sometidos a la decisión jurisdiccional exijan -por el derecho a la tutela jurisdiccional o el denominado principio de inexcusabilidad- de una resolución en sede jurisdiccional. En ese caso, a la jurisprudencia no le cabe solo una función interpretativa y aplicativa sino además, y en un sentido fuerte, una función integradora en virtud de la cual ha de construir o inferir a partir del mismo ordenamiento jurídico positivo, en primer lugar, un mandato normativo abstracto del cual va a hacer derivar un mandato jurídico concreto (la decisión) para aquel asunto necesitado de resolución jurisdiccional ${ }^{82}$. Dentro de este esquema y margen sí podría ser útil la introducción de la noción de doctrina jurisprudencial y la invocación de su infracción como motivo de casación para esos supuestos específicos.

Por otra parte, la afirmación precedente en orden a negarle el carácter de fuente formal del Derecho objetivo a la jurisprudencia no es óbice para sostener al tiempo que la jurisprudencia sí genera un vínculo jurídico preciso distinto del mandato jurídico que se contiene en ella ${ }^{83}$. Así, la valoración de un vínculo a la jurisprudencia unificada, de una parte, y la legitimidad del cambio y evolución jurisprudencial, de otra, imponen la necesidad de armonización de estas dos condiciones esenciales en un sistema jurídico como el nuestro (de Derecho positivo). La cuestión tiene su base de solución en la necesidad o deber de coherencia jurisprudencial que se le impone al juzgador por el principio de iurisprudentia novit curia (o interpretatio novit curia) que viene a complementar el clásico iura novit curia ${ }^{84}$, y que en consecuencia se traduce en la necesidad de que el juez no solo conozca el Derecho positivo, sino además que conozca la doctrina jurisprudencial imperante, y la aplique, salvo que entienda que aquella se encuentra superada, motivando la superioridad jurídica de la nueva orientación jurisprudencial que acoge, con lo cual podríamos decir que la doctrina

\footnotetext{
82 Vid. Boré (1988) pp. 377-379.

83 Solo así se pueden entender bien las observaciones de ZaCCARIA (2007) pp. 7-55, y las opiniones en que únicamente le reconocen una eficacia «gravitacional al precedente o moderada», pero no "vinculante e insuperable», tal como entendemos en nuestra tradición que operan los mandatos jurídicos abstractos contenidos en las fuentes del Derecho. Vid. sobre el fenómeno y la diferencia a DwOrKIN (1988) pp. 30-33, y también TARUFFo (2007) pp. 7-40.

${ }^{84}$ Sobre la comprensión en nuestra jurisprudencia civil de este aforismo y principio clásico de iura novit curia, vid. Hunter (2010) pp. 197-221.
} 
jurisprudencial genera un vínculo para el tribunal de casación y para los demás tribunales, en cuanto impone un deber de motivación específico para el cambio jurisprudencial, lo que hace posible la evolución consciente y razonada y evita la existencia de la dispersión patológica de criterios jurisprudenciales.

Estimamos que una explicación de este tipo pone las cosas en su justa medida, puesto que valoriza la estabilidad jurisprudencial (de la doctrina jurisprudencial), pero no se precipita a la formulación errónea de otorgarle el carácter de fuente de Derecho o de norma integrante del ordenamiento positivo que por principio no ha de tener en nuestro Derecho, puesto que el vínculo que genera una norma jurídica en sentido estricto es normativamente insuperable (no derrotable) para el juzgador y garantizado incluso bajo pena de prevaricación. La jurisprudencia no puede generar jamás un vínculo jurídico de esta especie $^{85}$. En último término el vínculo a la jurisprudencia no es normativo sino dialécti$\mathrm{Co}^{86}$, y se resuelve en el deber judicial de conocer la jurisprudencia interpretativa en vigor y de aplicarla o de motivar la superación-evolución de la misma ${ }^{87}$. En consecuencia, en un sistema jurídico como este es perfectamente legítimo modificar (abandonar) un criterio jurisprudencial previo con tal que se produzca con cargo a un deber de motivación ${ }^{88}$.

La posición que defendemos viene a ser ratificada en el Proyecto de CPC, en su artículo 414 inciso $2^{\circ}$, porque justamente le concede el valor dialéctico a la jurisprudencia unificada y establece el deber de motivación específico para la evolución-superación jurisprudencial, contemplando inclusive un cauce procesal específico para la anulación de la sentencia estimatoria del recurso extraordinario dada por la Corte Suprema que se separa infundadamente de su propia jurisprudencia. Con lo anterior, lo que se censura por este cauce impugnatorio especial es la falta de fundamentación al decidir separándose de su jurisprudencia, en tanto infracción de su deber de motivación específico que respalde su evolución jurisprudencial, derivado del principio iurisprudentia novit curia. No se censura una presunta «infracción» de su propia jurisprudencia, pues esta «infracción» no existe. De este modo el Proyecto viene a establecer un nuevo deber para la Corte Suprema, que se sostiene en este principio $^{89}$.

Este valor que se le quiere reconocer expresamente a la jurisprudencia emanada de la Corte Suprema también aparece garantizado por el deber que se le impone de declarar la doctrina jurisprudencial interpretativa-aplicativa en vigor (art. 413 del Proyecto), y por el aseguramiento de su difusión pública a través de su publicación electrónica, con expresa consignación de la doctrina jurisprudencial afirmada en las sentencias correspondientes (art. 415 del Proyecto).

85 En los Ordenamientos donde rige el sistema de precedentes se relativiza en buena medida la eficacia vinculante de aquellos. Así para el caso del Reino Unido, Bankowski, Maccormick y Marshall (1997) pp. 329-335, apuntan que la eficacia jurídica del precedente para la Corte (House of Lord) es superable o derrotable (defeasible). El precedente se mantiene hasta que la Corte estime que existen mejores razones que impongan una regla o nueva interpretación. Para el caso de USA, Summers (1997) pp. 368-371, también refiere al asunto de los grados de eficacia, y acaba de nuevo reconociendo la derrotabilidad del precedente como «fuente del derecho».

86 Interesantes resultan algunas reflexiones vinculadas a este punto realizadas por BELTRÁn (2012) pp. 587-606.

También Amoroso (2012) pp. 1-38 y 545-548.

87 Accatino (2002) pp. 559-582.

88 Vid. Blasco (2002) pp. 133-134.

89 El Proyecto de CPC vendría por esta vía a asumir las críticas que planteara ACCATINo (2002) pp. 575-579. 


\section{REFLEXIÓN CONCLUSIVA}

Como conclusión final podemos sostener, primero, que mediante el trabajo precedente se ponen de relieve los mecanismos de racionalización del funcionamiento de la casación, que en buena medida podrían ser considerados como utilizables en una futura reforma que busque la racionalización y el perfeccionamiento del régimen casacional en nuestro Derecho, asumiendo los contextos jurídico y práctico en que ella se desenvuelve actualmente. En el análisis antecedente hemos apuntado en qué medida cada medio de selección interno y externo puede ser aprovechable, y qué reparos técnico-procesales se pueden formular a los mismos. Obviamente la solución futura no pasa por el uso intenso de cada una de esas posibilidades. Probablemente lo más sensato sea la utilización bien calibrada de algunos de ellos, siempre en función de las necesidades reales que plantea nuestro sistema casacional: es eso lo que en líneas esenciales hemos intentado demostrar. Con lo anterior creemos haber probado que una discusión limitada a una opción entre el todo o nada, en torno a si en una futura reforma a la casación deba basarse en un sistema de selección que suponga la necesaria introducción de filtros judiciales discrecionales, resulta un análisis desenfocado y estrecho, y nos pone en la tesitura de tener que decidir ante un dilema falso.

En segundo lugar, cualquier reforma al régimen casacional que incida sobre la racionalización de la casación en nuestro Ordenamiento nos obliga a plantearnos la necesidad de ubicar una posición cierta a la doctrina jurisprudencial en que se encarnan las interpretaciones del Derecho imperantes. Desde luego esto resulta una necesidad frente a la realidad judicial que no logra ofrecer un grado aceptable de estabilidad a su jurisprudencia, pero también frente a los excesos de las posiciones teóricas y académicas que a veces sugieren ideas inexactas sobre este extremo. Y la propuesta más consistente que se puede ofrecer es aquella que le confiere un valor dialéctico (no normativo), al amparo de una formulación principial como aquella que se condensa en el aforismo de iurisprudentia (o interpretatio) novit curia y que ciertamente tiene el mérito de poner de relieve que el deber del juez no se agota en la necesidad de conocer y aplicar el Derecho positivo, sino además de estarse a (aplicar) la interpretación judicial dominante, salvo que asuma la función de proponer una interpretación superadora de la interpretación precedente, destinada a perfeccionar la faz aplicativa del Derecho, dando debida cuenta de esto por medio de la justificación de aquella.

\section{BIBLIOGRAFÍA CITADA}

Accatino, Daniela (2002): "El precedente en la cultura jurídica chilena», en Anuario de Filosofía Jurídica y Social (Valparaíso, EDEVAL) pp. 559-582.

Romero Seguel, Alejandro; Aguirrezábal Grünstein, Maite y Baraona González, Jorge (2008): "Revisión crítica de la causal fundante del recurso de casación en materia civil», Revista Ius et Praxis, vol. $14 \mathrm{~N}^{\circ}$ 1: pp. 225-259.

Ahumada Ruiz, María Ángeles (1994): «El 'certiorari'. Ejercicio discrecional de la jurisdicción de apelación por el Tribunal Supremo de los Estados Unidos», Revista española de Derecho constitucional, No 41: pp. 89-136.

Amoroso, Giovanni (2012): Il giudizio civile di cassazione (Milano, Giuffrè). 
Amrani Mekki, Soraya (2010): «La sélection des pourvois à Cour de Cassation», en VVAA, El recurso de Casación Civil (Cizur Menor, Thomson Reuter) pp. 629-654.

Atria, Fernando (2005): "Comentario jurisprudencial. La casación como problema», Revista de Derecho de la Universidad Adolfo Ibáñez, N²: pp. 249-353.

Bachellier, Xavier y Jobard-Bachellier, Marie Noëlle (2006): La technique de cassation (París, Dalloz, sexta edición).

Bankowski, Zenon; Maccormick, Neil y Marshall Geoffrey (1997): «Precedent in the United Kingdom», en MacCormick, Neil y Summers, Robert (edit.), Interpreting Precedents (Farnham, Ashgate) pp. 315-354.

Beltrán Calfurrapa, Ramón (2012): «La tópica jurídica y su vinculación argumentativa con el precedente y la jurisprudencia», Revista de Derecho de la Pontifica Universidad Católica de Valparaiso, vol. XXXIX: pp. 587-606.

Bonet Navarro, José (2006): «El carácter 'superextraordinario' del recurso de casación civil según el proyecto de reforma», en VVAA, Problemas actuales del proceso iberoamericano (Málaga, Cedma) pp. 387-400.

Boré, Jacque (1988): La cassation en materie civile (París, Sirey).

Bordalí Salamanca, Andrés (2007): "La unidad en la interpretación jurisdiccional de los derechos fundamentales: una tarea pendiente en el Derecho chileno", Revista Chilena de Derecho, vol. 34, N 3: pp. 517-538.

BranCaCCIO, Antonio (1992): "Conciliare esigenze opposte», en Il giudizio di cassazione nel sistema delle impugnazioni (Roma, Edizioni Tritone) pp. 279-290.

Brenner, Saul y Whitmeyer, Joseph (2009): Strategy on the United States Supreme Court (New York, Cambridge Press).

Blasco Gascó, Francisco (2010): El interés casacional (Cizur Menor, Aranzadi-Thomson).

Calamandrei, Piero (1945): La casación civil (trad. Sentís Melendo y Alcalá Zamora y Castillo, Buenos Aires, EJEA).

Cappelletti, Mauro (1972): "Parere iconoclastico sulla riforma del processo civile italiano», en Giustizia e società (Milano, Ed. Comunità) pp. 111-122.

Chiarloni, Sergio (1992): "La cassazione e le norme», en Il giudizio di cassazione nel sistema delle impugnazioni (Roma, Edizioni Tritone) pp 11-27.

Couchez, Gérard y Lagarde, Xavier (2014): Procédure civile (París, Sirey, décimo séptima edición).

Delgado Castro, Jordi (2010): «El certiorari: un agente extraño en manos de nuestra Corte Suprema", Revista Actualidad Jurídica, No 22: pp. 361-375.

Delgado Castro, Jordi (2011): «Examen crítico del recurso de unificación de jurisprudencia», Revista de Derecho de la Pontificia Universidad Católica de Valparaíso, vol. XXXVI: pp. 473-494.

Del Río Ferretti, Carlos (2013): "Función y finalidad de los recursos de naturaleza casacional: conceptos útiles para el diseño del nuevo Código Procesal Civil», en AguirrezÁBAL, Maite (edit.), Cuadernos de Extensión No 23 (Santiago, Universidad de los Andes) pp. 271-283.

DwOrKIN, Ronald (1988): El imperio de la justicia (trad. Claudia Ferrari, Barcelona, Gedisa). 
Ferrand, Frédérique (2010): «Les cas d'ouverture à cassation en droit français», en VVAA, El recurso de Casación Civil (Cizur Menor, Thomson Reuter) pp. 589-629.

Goodnow, Frank (1891): "The writ of certiorari», Political Science Quartely, vol. 6 N$^{\circ} 3$ : pp. 493-536.

GotTwald, Peter (2008): «Review Appeal to the German Federal Supreme Court after the reform of 2001», en ORTElls Ramos Manuel (coord.) Los recursos ante Tribunales Supremos en Europa (Madrid, España Difusión Jurídica) pp. 87-106.

Jobard-Bachellier, Marie Noëlle y Bachellier, Xavier (2006): La technique de cassation (París, Dalloz, sexta edición).

HABSCHEID, Walter (1994): "La giustizia civile in Germania», en VVAA, La giustizia civile nei paesi comunitari (Padova, Cedam), pp. 97-142.

Harnett, Edwards A. (2000): "Questioning Certiorari: Some Reflections Seventy-Five Years After The Judges' Bill», Columbia Law Review, vol. 100 N 7: pp. 1643-1738.

Hernández Ramos, Mario (2008): "La paulatina discrecionalidad y objetivación de la jurisdicción del Tribunal Supremo Federal de los Estados Unidos de América: el criterio de la importancia en la apelación y en el writ of certiorari», en Cuadernos de Derecho Público, 33, pp. 47-88.

Hunter Ampuero, Iván (2010): «El iura novit curiae en la jurisprudencia civil chilena», Revista de Derecho de la Facultad de Derecho de la Universidad Austral, No 2: pp. 197-221.

IsRael López, Ruth (2006): "Control de admisibilidad del recurso de casación en materia civil años 2000-2004», Revista de Estudios de la Justicia, Nº 8: pp 191-203.

Lagarde, Xavier y Couchez, Gérard (2014): Procédure civile (París, Sirey, décimo séptima edición).

Le Sueur, Andrew (2004): «Panning for Gold: Choosing Cases for Top-level Courts», en Le Sueur, Andrew (edit.) Building The UK'S New Supreme Court. National and Comparative Perspective (New York, Oxford University Press) pp. 271-292.

Linzer, Peter (1979): "The meaning of Certiorari Denials», Columbia Law Review, Vol. 79, $\mathrm{N}^{\circ}$ 7: pp. 1227-1305.

López SÁnchez, Javier (2002): El interés casacional (Madrid, Civitas).

LÓPEZ SÁNCHEZ, Javier (2010): "La reforma de la casación civil en España: propuestas y perspectivas», en El recurso de casación civil (Cizur Menor, Thomson Reuters-Aranzadi) pp. 87-126.

Maccormick, Neil; Bankowski, Zenon y Marshall Geoffrey (1997): «Precedent in the United Kingdom», en MacCormick, Neil y Summers, Robert, Interpreting Precedents (Farnham, Ashgate) pp. 315-354.

Mosquera, Mario y Maturana, Cristián (2010): Los recursos procesales (Santiago, Editorial Jurídica de Chile).

Nieva Fenoll, Jordi (2010): «La reforma de la labor del Tribunal Supremo y la 'unificación de doctrina'. Perspectiva de la introducción del modelo anglosajón en nuestro Derecho», en El recurso de casación (Santiago de Chile, Editorial AbeledoPerrot), 155 pp.

Ortells Ramos, Manuel (2010): «La casación en España: selección de recursos y carga de trabajo del Tribunal Supremo», en El recurso de casación civil (Cizur Menor, Thomson Reuters-Aranzadi) pp. 31-86. 
Pérez Ragone, Álvaro y Ortiz Pradillo, Juan Carlos (2005): Código Procesal Civil alemán [ZPO]. Traducción con un estudio introductorio al proceso civil alemán contemporáneo (Montevideo, Konrad Adenauer).

PivetTi, Marco (1992): "Osservazioni sul modello di Corte di cassazione», en Il giudizio di cassazione nel sistema delle impugnazioni (Roma, Edizioni Tritone) pp. 255-276.

Pizzorusso, Alessandro (1992): «La Corte Suprema di cassazione. Problemi organizzativi», en Il giudizio di cassazione nel sistema delle impugnazioni (Roma, Edizioni Tritone) pp. 181-197.

Posner, Richard (2011): Cómo deciden los jueces (Madrid, Marcial Pons).

Rigaux, François (1966): La nature du contrôle de la Cour de cassation (Bruxelles, Bruylant).

Rojas Sepúlveda, Mario (2010): «El rol de la Corte Suprema en el proyecto de nuevo Código Procesal Civil», Revista Actualidad Jurídica, No 22: pp. 315-360.

Romero Seguel, Alejandro (2004): La jurisprudencia de los tribunales de como fuente del Derecho (Santiago, Editorial Jurídica de Chile).

Romero Seguel, Alejandro (2013): El recurso de casación en el fondo civil. Propuesta para la generación de precedentes judiciales (Santiago de Chile, Thomson Reuters).

SASSANI, Bruno (2010): Il nome della "nomofilachia»: il ricorso per cassazione dal "quesito" al "filtro", en Bonet Navarro, José (dir.), El recurso de casación civil (Cizur Menor, Thomson Reuters), pp. 657-661.

Sсотт, Kevin M. (2006): «Shaping The Supreme Court's Federal Certiorari Docket», Justice System Journal, vol. 27 No 2: pp. 191-207.

Serra Domínguez, Manuel (1993): «El recurso de casación», en Montero Aroca, Juan (Coord.), La reforma de los procesos civiles (Madrid, Civitas) pp. 215-292.

Silvestri, Elissabetta (1992): «La selezione dei ricorsi», en Il giudizio di cassazione nel sistema delle impugnazioni (Roma, Edizioni Tritone) pp. 211-216.

Sommer, Udi (2010): «Beyond Defensive Denials: Evidencie from The Blackmun Files of a Broader Scope of Strategic Certiorari», Justice System Journal, vol. $31 \mathrm{~N}^{\circ}$ 3: pp. 316-341.

Summers, Robert (1997): "Precedent in the United State (New York State)», en VVAA, Interpreting Precedents (Farnham, Ashgate) pp. 355-406.

TARuffo, Michele (2007): Precedente e giurisprudenza (Editoriale Scientifica).

Tavolari Oliveros, Raúl (2013): «La eliminación de la casación civil: marchando contra los tiempos» (inédito).

Walter, Gerhard (2001): «I diritti fondamentali nel processo civile tedesco», en Rivista di Diritto Processuale, LVI, No 3 (Milano, Cedam) pp. 733-749.

Walter, Gerhard (2005): "The German Civil Procedure Reform Act: Much Ado About Nothing?», en Trocker y VARAno (Edits.), The Reform of Civil Procedure in Comparative Perspective (Torino, Giappichelli) pp. 67-89.

WheEler, Russell R (2004): «Intermediate Courts of Appeals and Their Relations with Top-level Courts: the US Federal Judicial Experience», en LE Sueur, Andrew, Building The UK'S New Supreme Court. National and Comparative Perspective, (New York, Oxford University Press) pp. 237-270.

Whitmeyer, Joseph y Brenner, Saul (2009): Strategy on the United States Supreme Court (New York, Cambridge Press). 
